\title{
Research Paper \\ Efficacy of transdiagnostic internet-based group therapy on distress tolerance and cognitive emotion regulation strategies on university students with adjustment disorder due to romantic breakup
}

\section{Elmira Ariana Kia ${ }^{1}$, Changiz Rahimi ${ }^{2}$, Nourollah Mohammadi ${ }^{2}$, Abdolaziz Aflak Seir $^{3}$}

1. Ph.D Student of Clinical Psychology, Department of Clinical Psychology, Faculty of Educational Sciences and Psychology, Shiraz University, Shiraz, Iran.

2. Professor, Department of Clinical Psychology, Faculty of Educational Sciences and Psychology, Shiraz University, Shiraz, Iran. 3. Assistant Professor, Department of Clinical Psychology, Faculty of Educational Sciences and Psychology, Shiraz University, Shiraz, Iran.

Citation: Ariana Kia E, Rahimi Ch, Mohammadi N, Aflak Seir A. Efficacy of transdiagnostic internet-based group therapy on distress tolerance and cognitive emotion regulation strategies on university students with adjustment disorder due to romantic breakup. J of Psychological Science. 2021; 20(106): 1749-1766.

URL: https://psychologicalscience.ir/article-1-1237-fa.html
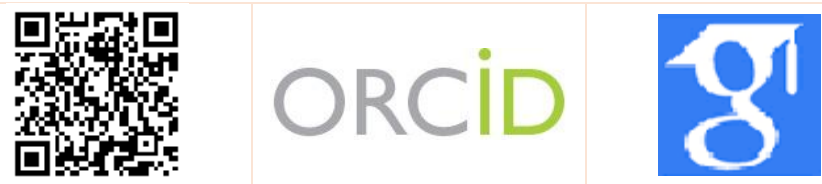

$\underline{10.52547 / J P S .20 .106 .1749}$

A R T I C L E I N F O A B S T R A C T

Keywords:

Romantic Breakup, Cognitive Emotion regulation strategies, Distress Tolerance, Transdiagnostic

Received: 29 Apr 2021 Accepted: 14 May 2021 Available: 22 Dec 2021
Background: Transdiagnostic therapy a structured and short-term approach that is designed to improve emotional, cognitive and behavioral problems by targeting the common causes of emotional and mood disorders. This protocol emphasizes how to experience and respond to excitements and seeks to improve the non-matching responses of excitement, cognition and behavior. However, there is a research gap on the efficacy of transdiagnostic therapy on romantic breakup.

Aims: The aim of this study was to evaluate of the efficacy of transdiagnostic internet-based group therapy on distress tolerance and cognitive emotion regulation strategies on university Students with adjustment disorder due to romantic breakup.

Methods: The present study was a quasi-experimental study with a pretest-posttest-follow-up design with a control group. Due to Epidemic corona disease, the statistical population included all students with romantic breakup across the country in 2020 in the age group of 18 to 38 years who were selected online after filling in the initial self-made form by the researcher and the diagnostic interview by purposeful sampling method entered the research.After completing the questionnaires, a group were selected and were randomly assigned to two groups: 15 people in the experimental group (transdiagnostic group therapy), and 15 people in the control group. 90 min sessions was performed for the experimental group. Subjects completed the distress tolerance (Simons \& Gaher, 2005) and cognitive emotion regulation (Garnefski, Kraaij, \& Spinhoven, 2002) in three stages: pretest, posttest and 1-month follow-up.

Results: Results of mixed analysis of variance showed a significant difference $(\mathrm{P}<0 / 05)$ between the post test scores of the experimental and control groups in the distress tolerance and cognitive emotion regulation strategies variables.

Conclusion: The results of this study indicated internet-based transdiagnostic group therapy can reduce the symptoms of romantic breakup.

* Corresponding Author: Changiz Rahimi, Professor, Department of Clinical Psychology, Faculty of Educational Sciences and Psychology, Shiraz University, Shiraz, Iran.

E-mail: crahimi2016@hotmail.com

Tel: (+98) 9177170543

2476-5740/ (C) 2021 The Authors. This is an open access article under the CC BY-NC-ND license

(https://creativecommons.org/licenses/by-nc/4.0/). 


\section{Extended Abstract}

\section{Introduction}

Parkes (2006) concluded in his study that losing the subject of love in adolescence is one of the greatest harms that can happen to individuals. The end of a romantic relationship is an event that puts a person at a disadvantage in terms of mental health and can affect all aspects of a person socially, mentally, physically and spiritually (Knöpfli, Cullati, Courvoisier, Burton-Jeangros, \& Perrig-Chiello, 2015). Thus, romantic relationships and to romantic breakup play an important role in the mental health of individuals, especially young people, and in general $70 \%$ of students experience psychological distress after romantic breakup (Collins \& Gillath, 2012). Therefore, given the prevalence of romantic breakup, focusing on the factors that aggravate and modify these conditions can be justified. Meanwhile, the strategies that people use to deal with harmful life conditions play an important role in mental health, and people who have difficulty managing their emotional responses have longer and more severe periods of their experience discomfort and are more likely to be depressed (Bardeen, Kumpula, \& Orcutt, 2013) or to experience stress (Phillips, Henry, Nouzova, Cooper, Radlak, et al., 2014). One of the most common of these strategies is emotion regulation using cognitive strategies. Cognitions or cognitive processes help people to regulate their emotions and feelings and not be overwhelmed by the intensity of emotions (Hassani, 2010).

On the other hand, research shows that people react differently to the consequences of romantic breakup, some people are more comfortable with the past and learn from their experiences, while others suffer from functional and mood disorders (Gilbert \& Sifers, 2011). Given that along with the romantic breakup, sadness, depression and anger appear in a person and endanger her mental health and interpersonal relationships, we must seek treatment that reduces this syndrome. The need to pay attention to psychological needs and psychological interventions to reduce emotional problems is becoming increasingly clear. In recent years, a number of treatment protocols have been developed using cognitive-behavioral principles to target significant problems caused by emotional disorders (anxiety and mood disorders) (Carpenter, Andrews, Witcraft, Powers, Smits, \& Hofmann, 2018). However, most people do not have access to these treatments. Norton and Hope argue that "this problem is not due to existing therapies but to the way they are presented" (Norton, 2012). In cognitive-behavioral approaches, the low prevalence of these therapies among therapists and the lack of access to these therapies for clients are two major problems in the way of specific therapies (Newby, McKinnon, Kuyken, Gilbody, Dalgleish, 2015). Transdiagnostic therapies (Barlow, Farchione, Firholme, Ellard, Boisseau, et al., 2011) were developed in response to these limitations. Given the strong empirical and theoretical evidence for the existence of more common factors than specific factors between anxiety and mood disorders and other related emotional disorders, these common factors are considered as rational on the emergence and conceptual foundations of transdiagnostic therapies. (Watkins, 2015).

Due to the prevalence of a new virus in Wuhan, China, called Quid disease-19 since December 2019 (Zhu, Wei, and New, 2020), online psychological interventions for people at risk, including students with romantic breakup who were quarantined last year Are essential .The experience of romantic breakup and the loss of a romantic relationship during student life is a very common phenomenon and often leads to poor academic performance and symptoms of anxiety and depression; therefore it needs special psychological attention. The use of the internet in the treatment of mental health is increasing due to its availability worldwide and people are looking for mental health information through the internet. Hence, Internet-based interventions are a unique opportunity to provide treatment to a large segment of the population. Research has also shown the effectiveness of online transdiagnostic therapy in emotional disorders such as anxiety and depression (Titov, Dear, Schwencke, Andrews, Johnston, et al., 2011; Johansson, Hesser, Ljótsson, Frederick, \& Andersson, 2012). Therefore, the aim of this study was to evaluate of the efficacy of transdiagnostic internet-based group therapy on distress tolerance and 


\section{Monthly Journal of Psychological Science}

Vol. 20, No. 106, Winter(January) 2021

cognitive emotion regulation strategies on university Students with adjustment disorder due to romantic breakup.

\section{Method}

The present study was a quasi-experimental clinical trial with a pretest-posttest design and a control group. The statistical population included all students suffer romantic breakup across the country in the age group of 18 to 38 years in 2020, who were selected online after completing the initial form of self-made demographics through advertising on the Telegram and Instagram channels of reputable universities.

Then, based on the entry and exit criteria, the study was conducted by available sampling method and after a diagnostic interview based on a short clinical interview (MINI-5) by the researcher. After selecting them online and performing the relevant questionnaires, a group was selected and randomly divided into two groups of 15 people in the experimental group (transdiagnostic therapy group) and 15 People were also replaced in the control group. At the end of the intervention, all of them were followed up online and also 1 month after the end of treatment. Inclusion criteria are: 18 to 38 years old student, have not left the relationship voluntarily, at least 1 month and maximum 6 months have passed since the end of the relationship, receiving a diagnosis of adjustment disorder with symptoms of anxiety and depression based on a psychologist interview and completing the adjustment disorder scale. Exclusion criteria: Having other mental disorders in DSM-5 based on the interview of a psychologist, the presence of severe signs of mental retardation, existence of high risk of suicide, and the presence of brain damage or other physical illnesses and receiving medical treatment based on the individual report.

Finally, the members of the sample were randomly assigned to the transdiagnostic therapy group (Barlow, 2011; translated by Mohammadi et al., 2017) and the experimental group underwent a 10session 90 min treatment group. And the waiting group did not receive treatment. At the end of the intervention, all of them were followed up online and also 1 month after the end of treatment, all of which were performed in Zoom software. Data analysis, descriptive statistical analysis, and repeated measures analysis of variance to control the effect of pre-test and evaluate the effectiveness of the study group in distress tolerance variables were cognitive emotion regulation strategies performed with SPSS 26 software.

Table 1. Results of repeated measures analysis of variance test to investigate the differences between groups in the distress tolerance variable in three stages: pre-test, post-test and follow-up

\begin{tabular}{|c|c|c|c|c|c|c|c|}
\hline Variable & Source of change & Average squares & $\mathrm{df}$ & Total squares & $\mathrm{F}$ & significance level & Effect size \\
\hline \multirow{3}{*}{ Tolerance } & levels & $22 / 898$ & $1 / 678$ & $38 / 422$ & $3 / 539$ & $0 / 045$ & $0 / 112$ \\
\hline & Groups & $27 / 778$ & 1 & $27 / 778$ & $2 / 455$ & $0 / 128$ & $0 / 081$ \\
\hline & levels * Group & $85 / 196$ & $1 / 678$ & $142 / 956$ & $13 / 169$ & $0 / 001$ & $0 / 320$ \\
\hline \multirow{3}{*}{ Absorption } & levels & $42 / 339$ & $1 / 594$ & $67 / 489$ & $13 / 349$ & 0/001 & $0 / 323$ \\
\hline & Groups & $15 / 211$ & 1 & $15 / 211$ & 0/970 & $0 / 333$ & $0 / 033$ \\
\hline & levels * Group & $18 / 583$ & $1 / 594$ & $29 / 622$ & $5 / 859$ & 0/009 & $0 / 173$ \\
\hline \multirow{3}{*}{ Assessment } & levels & $34 / 994$ & $1 / 774$ & $62 / 067$ & $10 / 228$ & 0/001 & $0 / 268$ \\
\hline & Groups & $426 / 844$ & 1 & $426 / 844$ & $6 / 379$ & $0 / 017$ & $0 / 186$ \\
\hline & levels * Group & $46 / 245$ & $1 / 774$ & $82 / 022$ & $13 / 517$ & 0/001 & $0 / 326$ \\
\hline \multirow{3}{*}{ Regulation } & levels & $17 / 954$ & $1 / 728$ & $31 / 022$ & $6 / 238$ & $0 / 006$ & $0 / 182$ \\
\hline & Groups & $211 / 600$ & 1 & $211 / 600$ & $11 / 719$ & $0 / 002$ & $0 / 295$ \\
\hline & levels * Group & $63 / 121$ & $1 / 728$ & $109 / 067$ & $21 / 933$ & $0 / 001$ & $0 / 439$ \\
\hline
\end{tabular}

Table 2. The results of repeated measures analysis of variance test to examine the differences between groups in the variable of emotional cognitive regulation strategies in three stages of pre-test, post-test and follow-up

\begin{tabular}{cccccccc}
\hline Variable & $\begin{array}{c}\text { Source of } \\
\text { change }\end{array}$ & $\begin{array}{c}\text { Average } \\
\text { squares }\end{array}$ & df & $\begin{array}{c}\text { Total } \\
\text { squares }\end{array}$ & F & $\begin{array}{c}\text { significance } \\
\text { level }\end{array}$ & Effect size \\
\hline positive refocusing, & levels & $39 / 660$ & $1 / 540$ & $61 / 089$ & $6 / 339$ & $0 / 007$ & $0 / 185$ \\
planning & Groups & $1 / 111$ & 1 & $1 / 111$ & $/ 016$ & $0 / 899$ & $0 / 001$ \\
positive appraisal, and & levels * Group & $82 / 508$ & $1 / 540$ & $127 / 089$ & $13 / 188$ & $0 / 001$ & $0 / 320$ \\
putting into perspective & levels & $17 / 875$ & $1 / 948$ & $34 / 822$ & $4 / 002$ & $0 / 025$ & $0 / 125$ \\
\hline
\end{tabular}




\begin{tabular}{|c|c|c|c|c|c|c|c|}
\hline Variable & $\begin{array}{l}\text { Source of } \\
\text { change }\end{array}$ & $\begin{array}{c}\text { Average } \\
\text { squares }\end{array}$ & df & $\begin{array}{c}\begin{array}{c}\text { Total } \\
\text { squares }\end{array} \\
\end{array}$ & $\mathrm{F}$ & $\begin{array}{c}\text { significance } \\
\text { level }\end{array}$ & Effect size \\
\hline \multirow{5}{*}{ self- blame } & levels * Group & $63 / 071$ & $1 / 948$ & $122 / 867$ & $14 / 120$ & $0 / 001$ & $0 / 335$ \\
\hline & levels & $27 / 641$ & $1 / 752$ & $48 / 422$ & $12 / 658$ & $0 / 001$ & $0 / 311$ \\
\hline & Groups & $2 / 500$ & 1 & $2 / 500$ & $0 / 199$ & $0 / 659$ & 0/007 \\
\hline & levels * Group & $50 / 499$ & $1 / 752$ & $88 / 467$ & $23 / 126$ & $0 / 001$ & $0 / 452$ \\
\hline & levels & $52 / 180$ & $1 / 902$ & $99 / 267$ & $15 / 257$ & 0/001 & $0 / 353$ \\
\hline \multirow[t]{2}{*}{ blaming others } & Groups & $15 / 211$ & 1 & $15 / 211$ & $1 / 198$ & $0 / 283$ & $0 / 041$ \\
\hline & levels * Group & $49 / 353$ & $1 / 902$ & $93 / 889$ & $14 / 430$ & $0 / 001$ & $0 / 340$ \\
\hline \multirow{3}{*}{ rumination } & levels & $21 / 824$ & $1 / 883$ & $41 / 089$ & $3 / 751$ & $0 / 032$ & $0 / 118$ \\
\hline & Groups & $139 / 378$ & 1 & $139 / 378$ & $4 / 903$ & $0 / 035$ & $0 / 149$ \\
\hline & levels * Group & $30 / 889$ & $1 / 883$ & $58 / 156$ & $5 / 308$ & $0 / 009$ & $0 / 159$ \\
\hline \multirow{3}{*}{ catastrophising } & levels & $27 / 395$ & $1 / 828$ & $50 / 067$ & $10 / 315$ & $0 / 001$ & $0 / 269$ \\
\hline & Groups & $217 / 778$ & 1 & $217 / 778$ & $11 / 767$ & $0 / 002$ & $0 / 296$ \\
\hline & levels * Group & $35 / 031$ & $1 / 828$ & $64 / 022$ & $13 / 190$ & 0/001 & $0 / 320$ \\
\hline \multirow{3}{*}{ acceptance } & levels & $51 / 323$ & $1 / 562$ & $80 / 156$ & $17 / 130$ & $0 / 001$ & $0 / 380$ \\
\hline & Groups & $42 / 711$ & 1 & $42 / 711$ & $2 / 914$ & 0/099 & 0/094 \\
\hline & levels * Group & $47 / 908$ & $1 / 562$ & $74 / 822$ & $15 / 990$ & $0 / 001$ & $0 / 363$ \\
\hline
\end{tabular}

\section{Results}

The results of descriptive findings showed that the mean age of participants in the experimental group was 26.53 and the standard deviation was 4.68 and in the control group the mean age of participants was 25.40 and the standard deviation was 4.54 . Out of 15 people in the experimental group, $6(40 \%)$ have a bachelor's degree, $6(40 \%)$ have a master's degree and $1(6.7 \%)$ has a doctorate and $2(13.3 \%)$ and $1(6 / 7)$ had a professional doctoral degree. Also, out of 15 controls, 5 (33.3\%) have a bachelor's degree, 7 $(46.7 \%)$ have a master's degree and $2(13.3 \%)$ have a doctorate $(6.7 \%)$. Have had a professional doctoral degree. Also in the experimental group, 13 (86.7\%) were girls and $2(13.3 \%)$ were boys, and in the control group, $10(66.7 \%)$ were girls and $5(33.3 \%)$ were boys. In the inferential findings section, repeated measures analysis of variance was used to analyze the data, and the assumption that the data were normal was performed by Kalmogorov-Smirnov test. The results of this test showed that all variables in the pretest, post-test and follow-up follow the normal distribution. In order to check the assumption of uniformity of covariances or equality of covariances with total covariance, the mauchly's test of sphericityis was used. If the significance of the mauchly's test of sphericityis higher than 0.05 , the mauchly's test of sphericityis test is usually used, and if it is not confirmed, the conservative GreenhouseGeisser test is used to analyze the variance of the repeated measures. Since the results of the mauchly's test of sphericityis were significant $(\mathrm{P}<0.05)$, the
Greenhouse-Geiser index was used and for pairwise comparisons, the Bonferroni post hoc test was used, which finally confirmed all these assumptions.

Based on the results, the mean scores of the distress tolerance variable in the transdiagnostic treatment group increased compared to the control group in the post-test and follow-up stages compared to the pretest stage. It does not show much change, but in the transdiagnostic therapy treatment group, we see an increase in the scores of positive cognitive regulatory factors and a decrease in the scores of negative cognitive regulatory factors in the post-test and follow-up stages compared to the pre-test.

Based on the findings obtained in Table 1 , the difference between the scores of the components of tolerance ( $\mathrm{P}<0.05)$, absorption $(\mathrm{P}<0.01)$, evaluation $(\mathrm{P}<0.01)$ and adjustment $(\mathrm{P}<0.01)$ in three stages of research is significant. Based on the findings in Table 2 , the difference between the scores of the positive focus/planning components $(\mathrm{P}<0.01)$, positive evaluation / broader perspective $(\mathrm{P}<0.05)$, self-blame $(\mathrm{P}<0.01)$, blame others $\quad(\mathrm{P}<0.01)$, rumination $(\mathrm{P}<0.05)$, catastrophic $(\mathrm{P}<0.01)$ and acceptance $(\mathrm{P}$ $<0.01)$ were significant in three stages of the study.

\section{Conclusion}

The results of the analysis showed that the transdiagnostic therapy group is effective in distress tolerance of students with adjustment disorder due to romantic breakup. These results are consistent with the findings of Laposa and et al. (2017) and the research of Nargesi and et al (2019). 
Explaining this result, it should be noted that the end of a special romantic relationship causes distressing symptoms in many people who have experienced it. An important part of transdiagnostic therapy is understanding the adaptive nature of emotions and increasing emotional awareness using mindfulness techniques. In the sessions, the clients are taught that all emotions, whether positive or negative, are important and necessary. Our goal is not to eliminate, but to identify, tolerate and cope with negative emotions. Awareness of emotions and its acceptance has played an important role in treatment because if a person does not accept his particularly negative emotions, he has not been able to gather all his energy sources and find a suitable solution in that situation (Behar, DiMarco, Hekler, Mohlman, \& Staples, 2009).

The results of the analysis also showed that the transdiagnostic therapy group is effective on cognitive emotion regulation strategies of students with adjustment disorder due to romantic breakup. These results are consistent with the findings of Talkovsky et al. (2017), Zemestani and Imani (2015), Ashena et al. (2021), Abdolkarimi et al. (2015), Azimi et al. (2015) and Fadaei et al (2015).

In explaining the effect of this intervention method on emotional dysregulation as one of the factors involved in the development of emotional disorders (Gross, 2014) it can be said that transdiagnostic interventions teach people how to deal with inappropriate emotions in order to respond to their emotions in a more adaptive way. The goal of this method is to reduce the severity and occurrence of emotional habits, reduce the amount of damage and increase function by regulating emotion regulation habits.Transdiagnostic therapy, instead of inhibiting or controlling negative emotions, understands the adaptive nature of emotions and increases emotional awareness by using mindfulness techniques (Barlow, 2017). All of these skills, by modifying emotional regulation habits, lead to a reduction in the difficulty of emotional regulation and return emotions to a functional level that has a direct impact on emotional symptoms (Bakhshipour, Alilou, Farnam, and Abdi, 2012).

\section{Ethical Considerations}

Compliance with ethical guidelines: This article is taken from the doctoral dissertation of the first author in the field of clinical psychology in Shiraz University and is approved by Shiraz University of Medical Sciences and has the code of ethics IR.SUMS.REC.1400.070.

Funding: This research is in the form of a doctoral dissertation without financial support.

Authors' contribution: The first author is the main researcher of this research. The second author is the supervisor and the third and fourth authors are the advisory professors of the dissertation. Conflict of interest: The authors do not disclose any conflict of interest in this study.

Acknowledgments: The authors of the article sincerely thank all the participants and individuals who helped to carry out this research as well as possible. 


\section{اثربخشى تروه درمانترى فراتشخيصى اينترنتى بر تحمل بريشانى و راهبردهاى نظمجويى شناختى هيجان دانشجويان

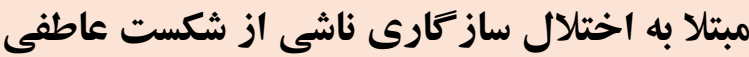

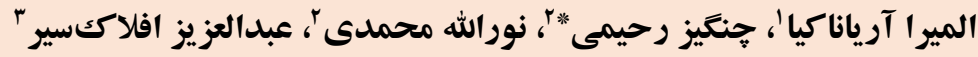 \\ ا. دانشجوى دكترى روانشناسى بالينى، گروه روانشناسى بالينى، دانشكده علوم تربيتى و روانشناسى، دانشخاه شيراز، شيراز، اير ائان.

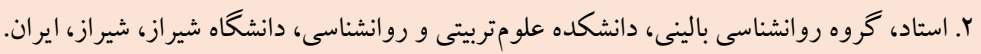

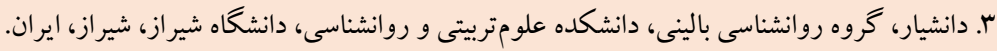

\section{جكيله}

زمينه: درمان فراتشخيصى رويكردى ساختارمند و كو تاه مدت است كه با هدف قرار دادن عوامل مشترك اختلالات هيجانى و خلقى براى

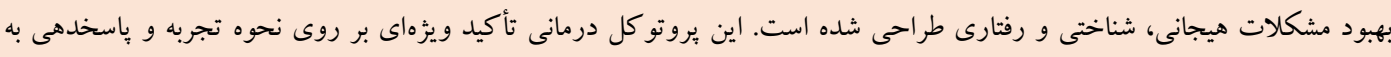
هيجانها دارد و سعى در بهبود ياسخهاى سازشنايافته هيجان، شناخت و رفتار مى كند. اما درمورد اثربخشى درمان فراتشخيصى بر شكست عاطفى شكاف تحقيقاتى وجود دارد. هدف: اين يُوهش با هدف بررسى اثربخشى گروه درمانگرى فراتشخيصى اينترنتى بر تحمل يريشانى و راهبردهاى نظمجويى شناختى

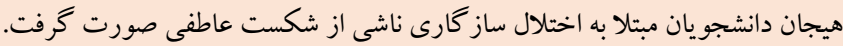
روش: اين ئوهش از نوع كار آزمايى بالينى شبه آزمايشى با طرح ييش آزمون - پيس آزمون و گروه گُ اه بود. با توجه به شيوع بيمارى كرونا،

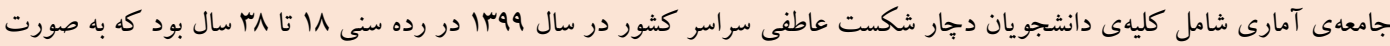

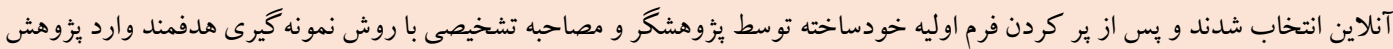

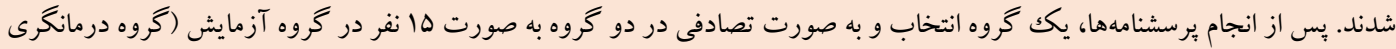

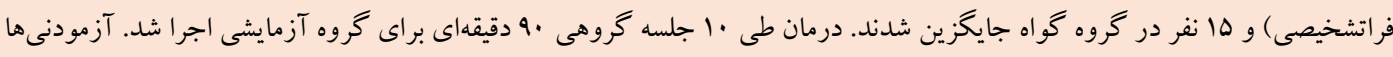

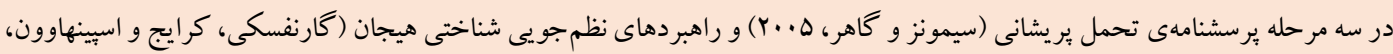

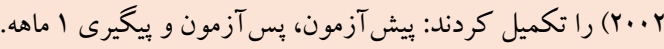

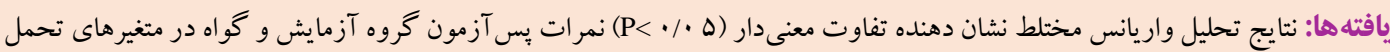
ير يشانى و راهبردهاى نظم جويى شناختى هيجان بود. نتيجه كيرى: از يافتهاى اين يزوهش استباط مىشود كه گروه درمانكرى فراتشخيص اينترنتى مى تواند علايم ناشى از شكست عاطفى را
مشخصات مقاله

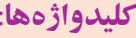

شكست عاطفى،

راهبردهاى نظم جويى شناختى

هيجان،

تحمل بريشانى،

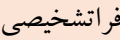

* نويسنده مسئول: جنگيزيز رحيمى، استاد، گروه روانشناسى بالينى، دانشكده علومترييتى و روانشناسى، دانشكاه شيراز، شيراز، ايران. رايانامه: crahimi2016@hotmail.com 
راهبردهاى سازشنايافته (ملامت خود، ملامت ديخران، بذيرش، فاجعه

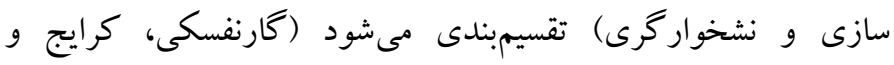

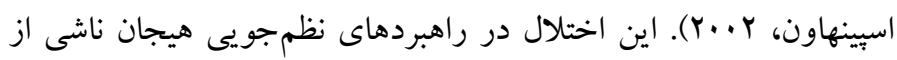
استرس مى تو اند منجر به اختلالات خلقى و اضطر ابى شود (هافمن، ساوير،

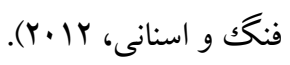

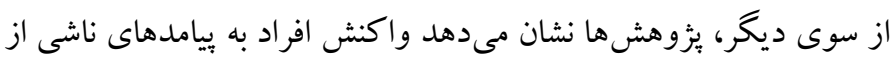

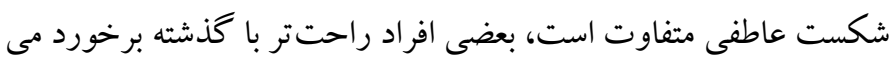
كنند و بدنبال بند آموزى از تجربه هايشان هستند، درحالى كه برخى إنى ديخر

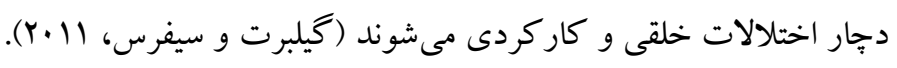

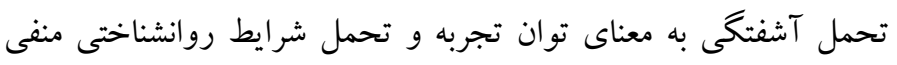

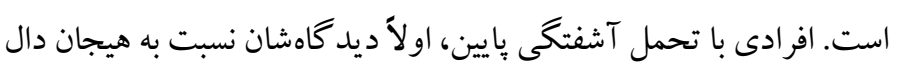
بر غيرقابل تحمل بودن آن است و نمى تو انند با آشفتكى و بريشانى مقابله

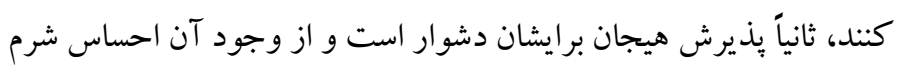
و ويريشانى مى كنند و در مواجهه با هيجانات احساس ناتوانى مى كنند.

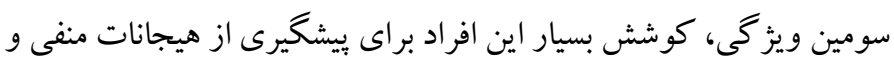

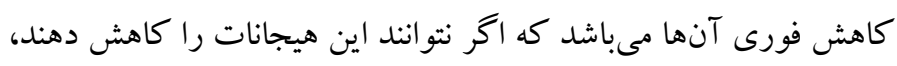

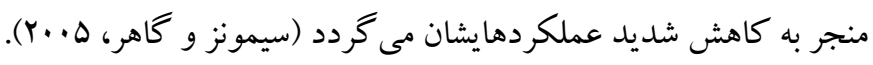

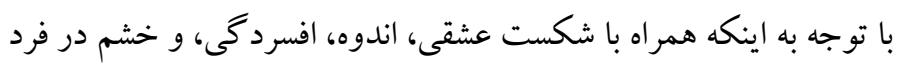
ظاهر مىشود و سلامتروان و روابط بينفردى او را با خطر مواجه مى كند بند

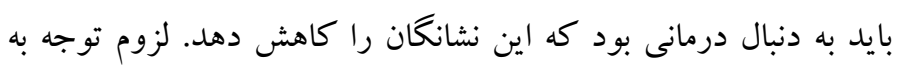

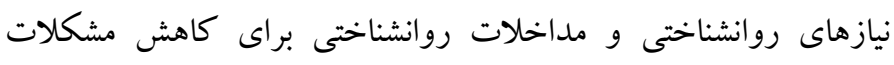
هيجانى بيش از ييش روشن است. در طى سالهاى اخير تعدادى از

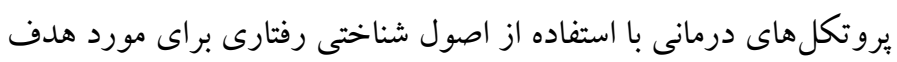
قرار دادن مشكلات جشمخير ناشى از اختلالهاى هيجانى (اختلال

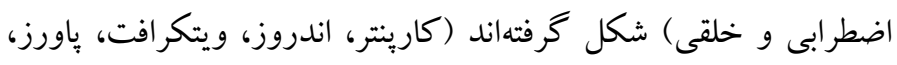
اسميت و هافمن، 1) (Y). اما، اغلب افراد به اين درمانها دسترسى ندارند. نورتن و هوٍ معتقدند "اين مشكل از درمانهاى موجود نيست بلكه ناشى هـ

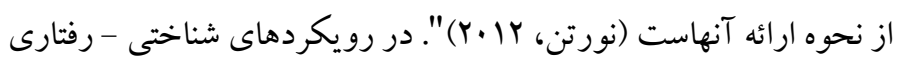

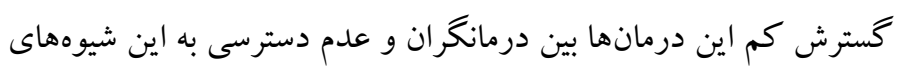

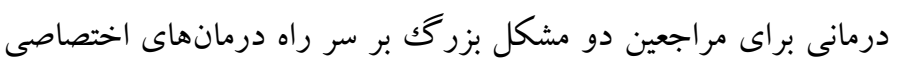

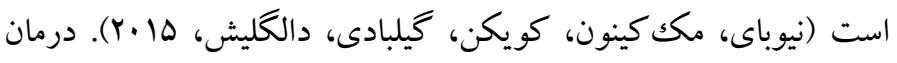
هاى فراتشخيصى (بارلو، فارشيون، فيرهلم، الارد، بوئيسو و همكاران،
مقلمهه

در دوره جوانى افراد دنبال رابطه با جنس مكمل هستند و به تدريج يافتن

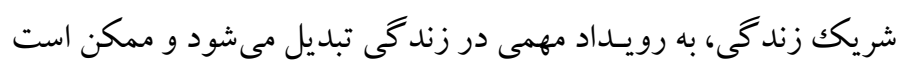

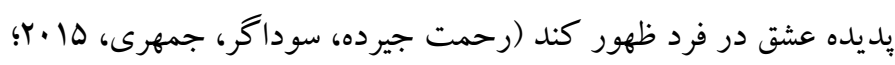

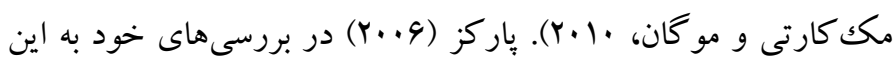

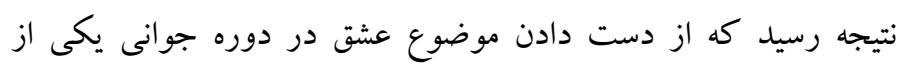

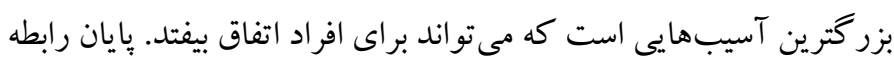

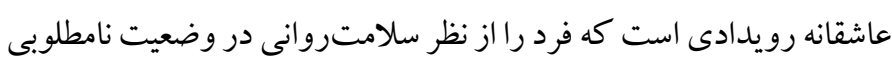

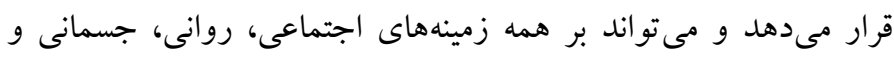

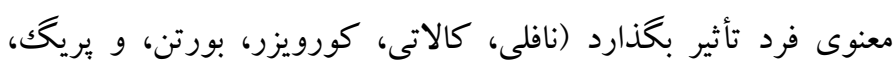

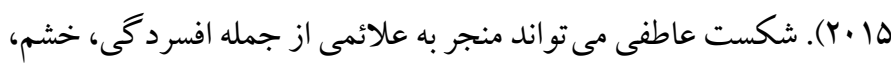

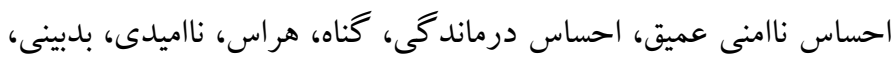

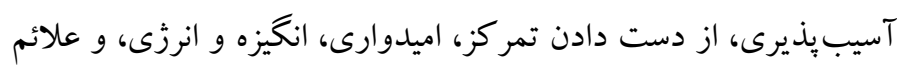

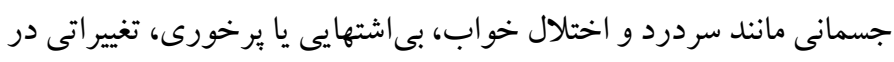

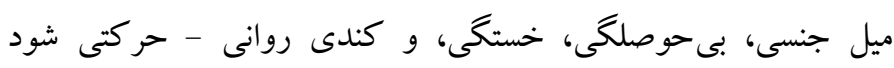

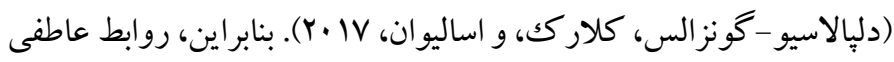
و شكست هاى عاطفى نقش مهمى در بهداشت روانى افراد به ويزه جوانان

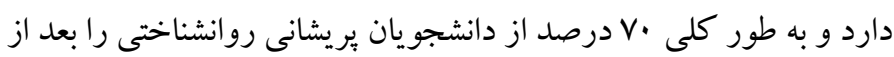

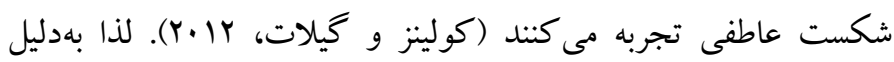
كسترش شكست عاطفى، تمر كز بر عوامل تشديد كننده و تعديل كننده

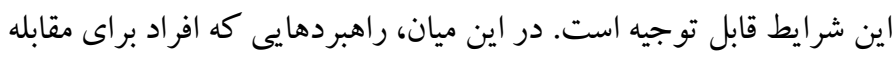

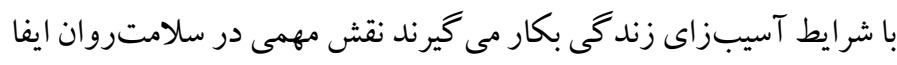

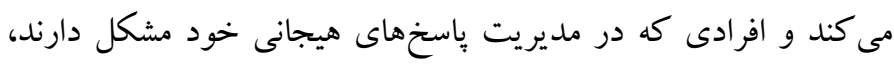

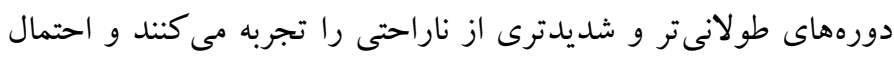

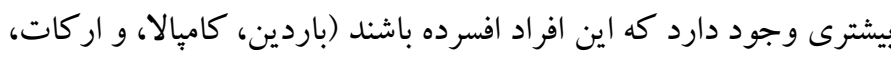

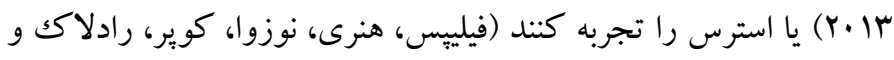

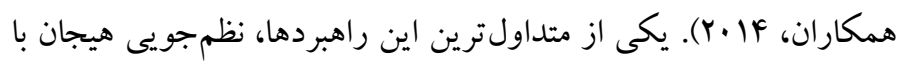

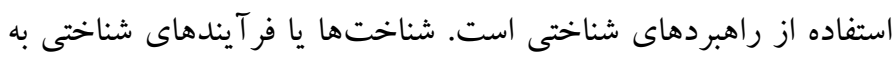
افراد كمك مى كند كه هيجانها و احساسهاى خود را تنظيم كرده و

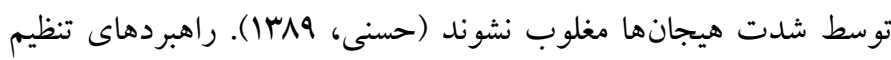
شناختى هيجان به دو دسته كلى، راهبردهاى سازش يافته (ارزيابى مجدد

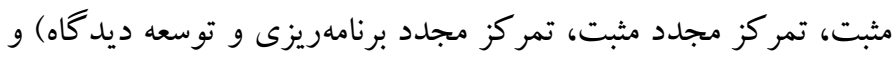


فردى و اجتماعى در دانشجويان دختر (عظيمى، اميدى، شفيعى و نادمى،

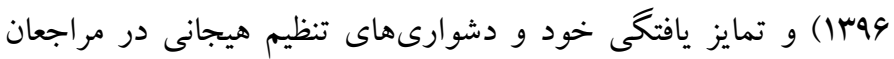

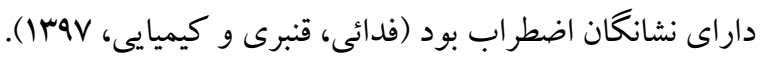

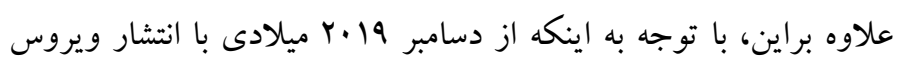

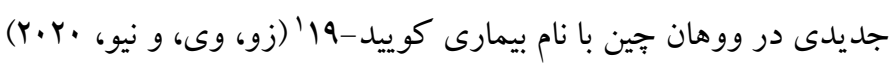

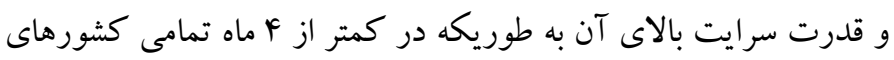

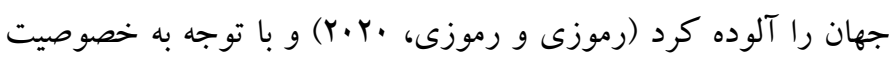

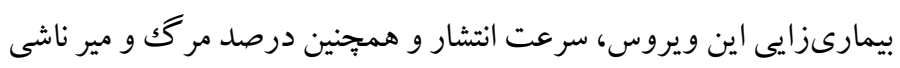
از آن كه ممكن است وضعيت بهداشت سلامتروان افراد در سطوح مختلف جامعه از بيماران مبتلا، كاركنان مراقبتهاى بهداشتى و درمانى،

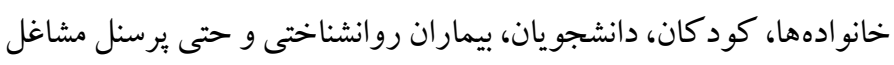

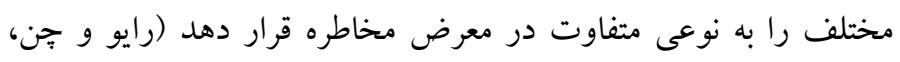

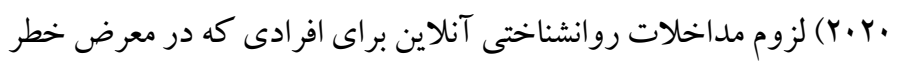
بيشترى هستند و از آن جمله دانشجويانى كه در طى سال كذشته در قرنطينه به سر مىبرند و دجار شكست عاطفى شدهاند را برجسته مى سازد. تجربه

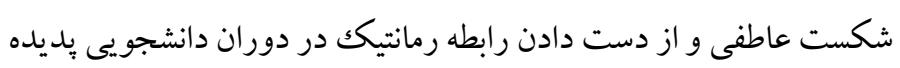

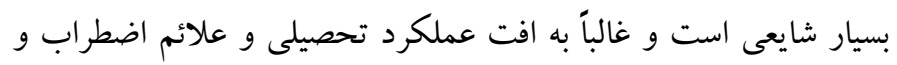
افسردگى منجر مى شود؛ لذا نيازمند توجه روانشناختى ويزه است. استفاده از اينترنت در درمان سلامتروان به علت در دسترس بودن درد سرد سواسر جهان رو به افزايش است و مردم به دنبال اطلاعات سلامتروان از طريق ايترنت

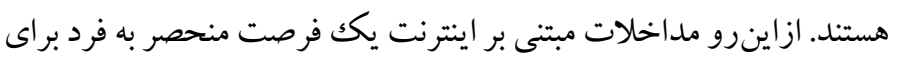

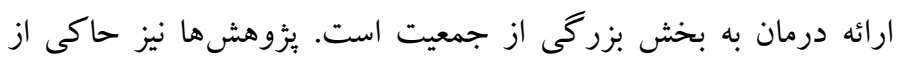

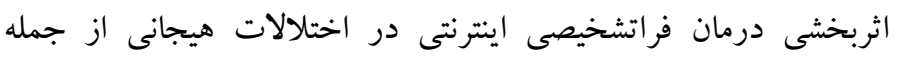

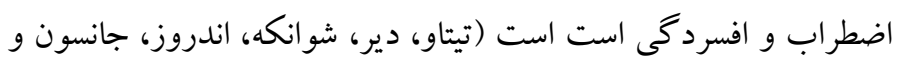

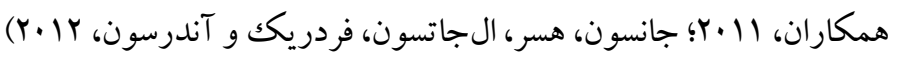
كمبود تحقيقات كنترلشده در مورد شكست عاطفى نه تنها در ايران بلكه در كشورهاى ديخر نيز مطرح است، و علىرغم گزارش اثربخشى طرحواره

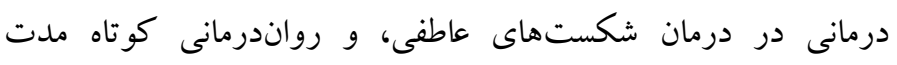

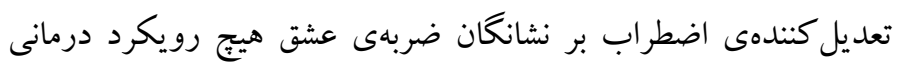

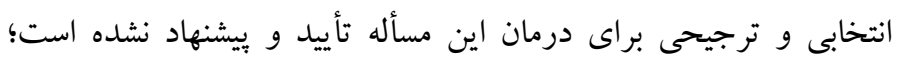

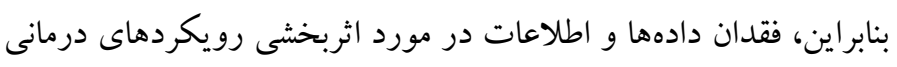

(Y. I) در ياسخ به اين محدوديتها ايجاد شدند. با توجه به شواهد تجربى

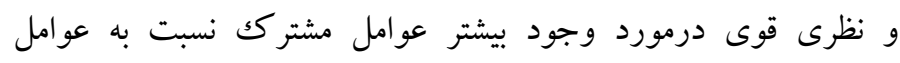

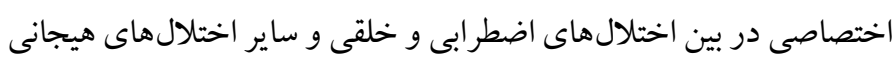

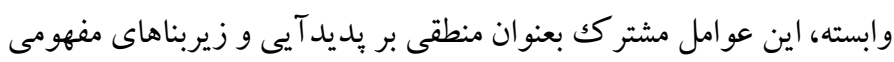

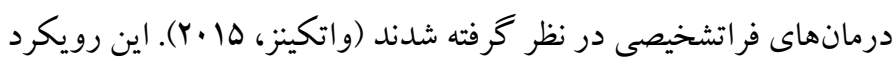

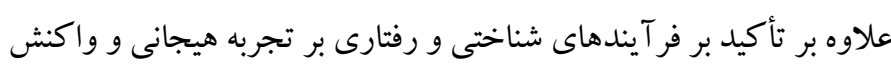

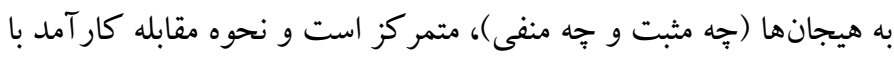

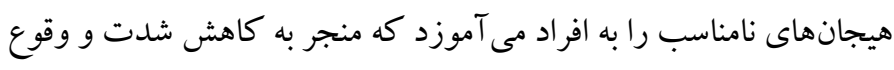

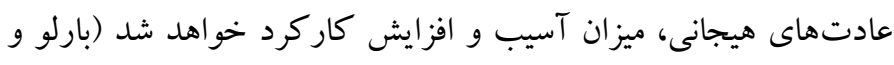

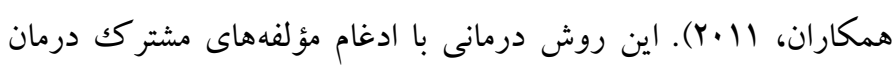

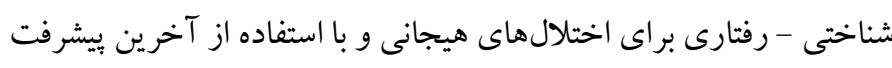

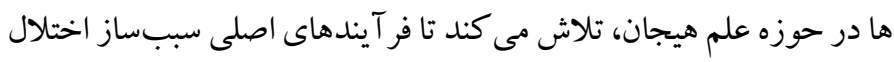

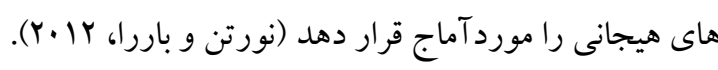

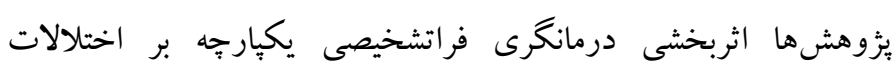

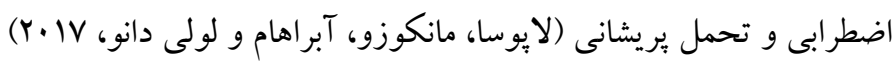

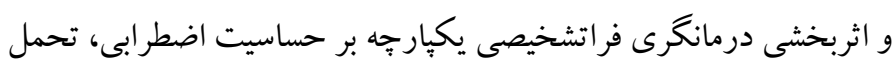

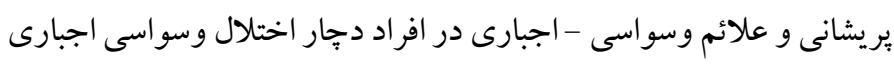

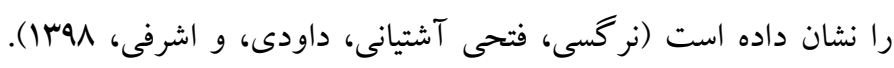

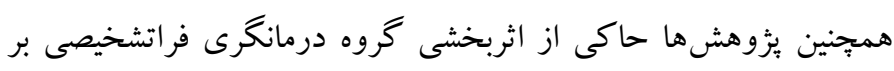

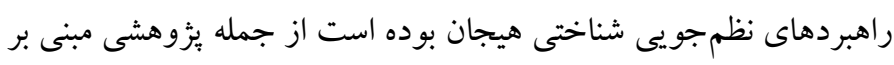

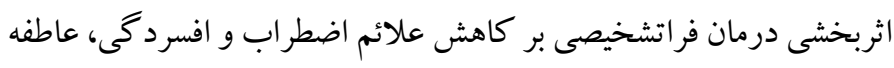
منفى، بازدارى رفتارى و مشكلات تنظيم هيجانى در بيماران مبتلا به اختلال

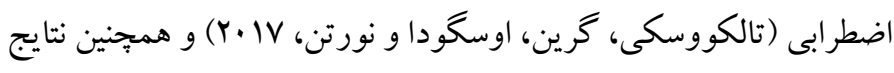

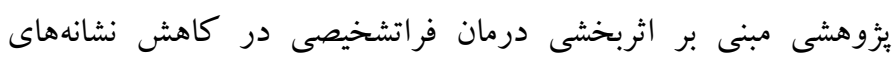

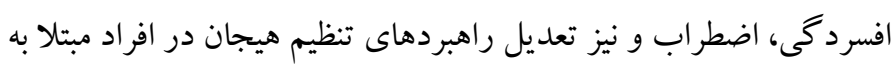

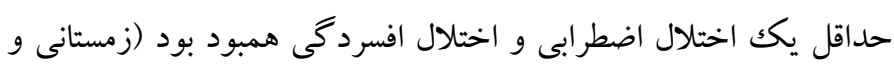

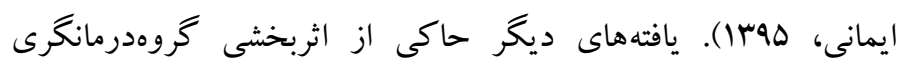

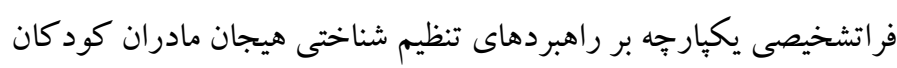

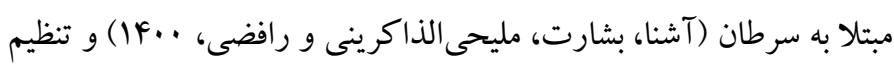

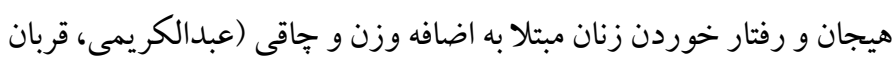

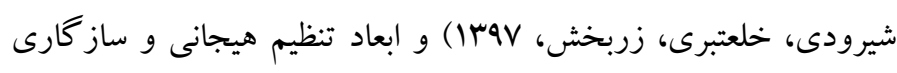

\section{COVID-19}


نشانهاى شديد كندى روانى حر كتى، عدم وجود خطر بالاى خود كشى با

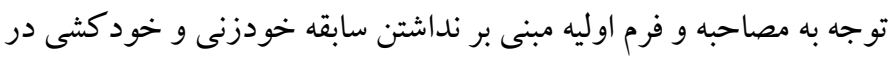
كذشته، و عدم وجود آسيب مغزى يا ساير بيمارىهاى جسمانى و و عدم دريافت درمان دارويى براساس كزارش خود فرد. ملاككهاى خروج

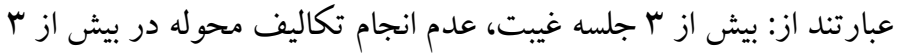

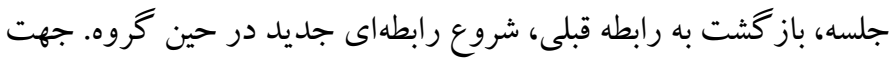

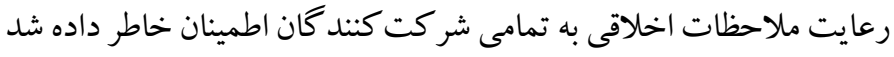

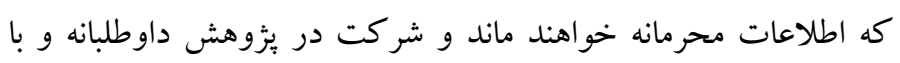
رضايت خود فرد است و شركت كند كان در صورت عدم تمايل به ادامه شركت در درمان با اطلاع قبلى مىتوانند يُوهش را ترك كنند و

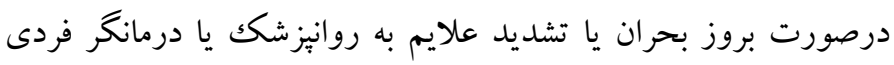

$$
\text { ارجاع خواهند شد. }
$$

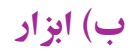

فرم اطلاعات اوليه جمعيتشناختى با اين فرم كه توسط خود بزوهشكر ساخته شد، قبل از شروع گروه درمانى و در فر آيند غربالكرى اعضاى نمونه

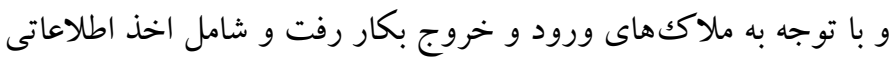
در زمينه نام، جنسيت، سن، رشته، مقطع تحصيلى، دانشخاه، مدت ورته رابطه عاطفى، مدت زمانى كه از پايان رابطه عاطفى سبرى شده، خواسته يا

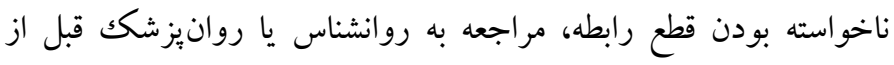

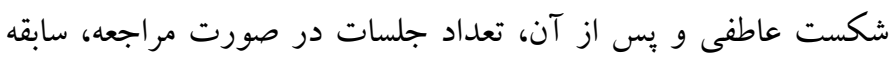

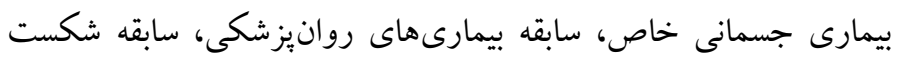

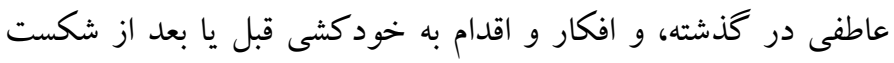
عاطفى بود.

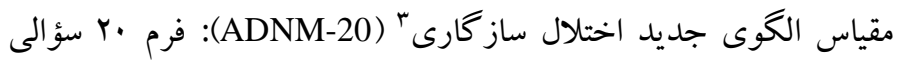

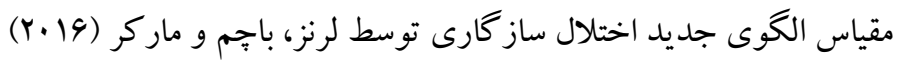

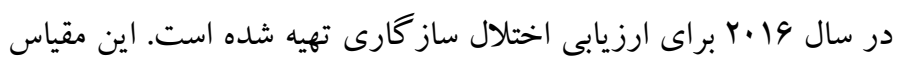
شامل ·r سؤال است و ياسخ ها در يك طيف ليكرت F درجهاى از هر خز (1) تا اغلب (F) مىباشد. علايم اصلى توسط ^ سؤال و علايم فرعى توسط

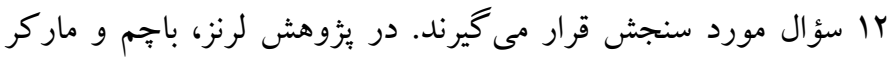

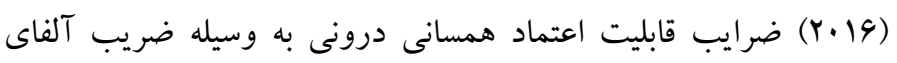

${ }^{3}$. Adjustment Disorder New Model-20
مختلف از جمله اثربخشى رويكرد فر اتشخيصى به منظور درمان دانشجويان دجار شكست عاطفى، ضرورت و اهميت اين يزوهش را به به خوبى تبين

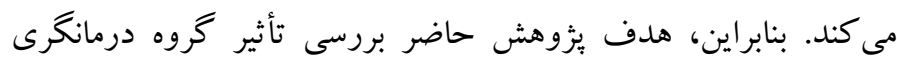

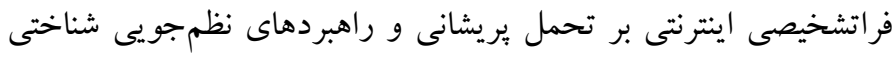

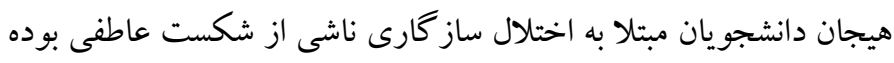

الف) طرح يثوهش و شر كت كنند

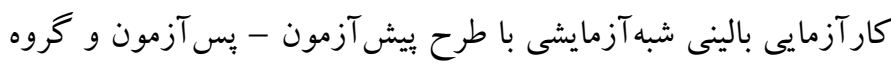

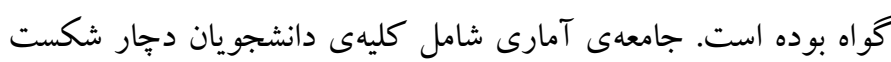

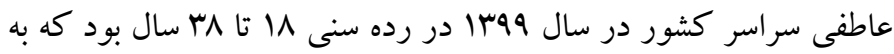

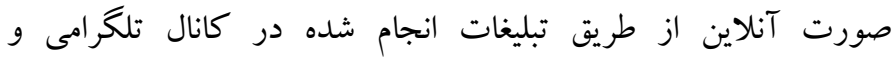
اينستاگرامى دانشگاههاى معتبر (دانشگاه تهران، دانشگاه شريف، دانشگاه

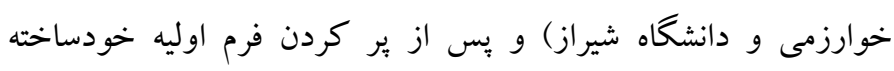

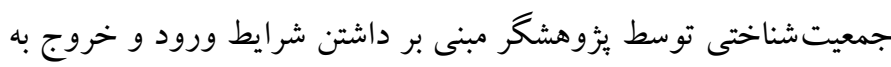

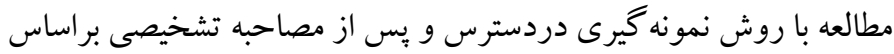

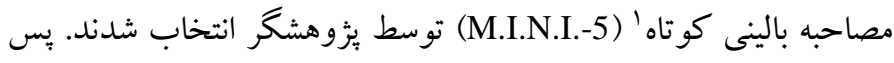
از انتخاب آنها به صورت آنلاين و تصويرى و در نرمافزار زوم در مدت بداه

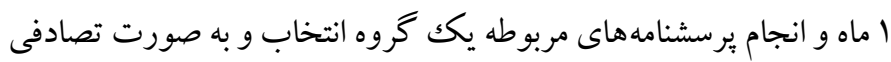

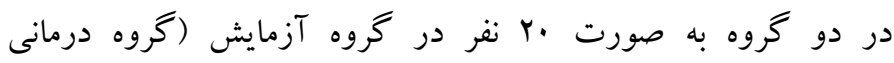

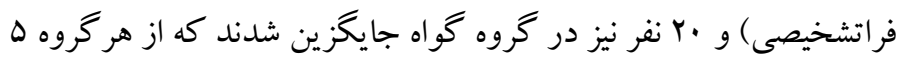
نفر به دلايل مختلف از جمله غيبت مكرر يا باز گشت به رابطه قبلى و... از

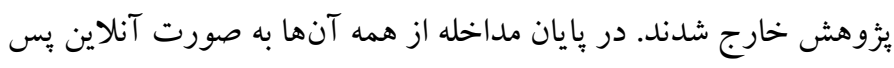

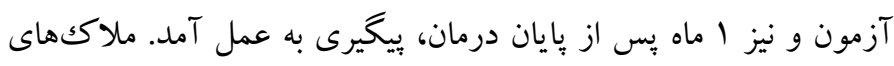
ورود عبارتند از: دانشجوى ما تا مب ساله، به خواست خود از رابطه خارج نشده باشند، حداقل 1 ماه و حداكثر 9 ماه از بايان رابطه كذشته باشد،

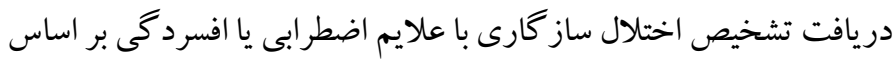
مصاحبه روانشناس و ير كردن مقياس اختلال ساز كارى، عدم ابتلا به ساير باري

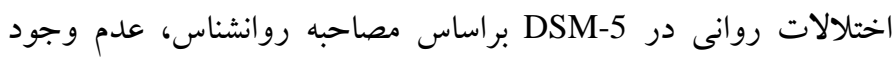

1. MINI International Neuropsychiatric Interview

2. Demograhic Information Questionarie 
راهبردهاى سازشيافته شناختى نظمجويى هيجان (يذيرش، تمركز مجدد مثبت، تمركز مجدد برنامهريزى، ارزيابى مثبت مجدد و كم اهميت شمارى) و راهبردهاى سازشنيافته شناختى نظمجويى هيجان كه شامل (خودسرزنشكرى، سرزنش ديخران، فاجعه آميزيندارى و نشخوار فكرى) مىباشد. كه تعداد ·r ماده يرسشنامه راهبردهاى سازش يافته و 19 ماده ديخر راهبردهاى سازشنيافته شناختى نظمجويى هيجان را مىسنجند. يّاسخهاى اين پيرسشنامه در يكك بيوستار ها درجهاى (هميشه، اغلب اوقات، معمولاً، گاهى و هر گز) جمع آورى مى گردد و به ترتيب از جِّ به راست از ا تا ها نمره كذارى مى شوند. نمرات به دست آمده با هم جمع شده و نمرهى كل

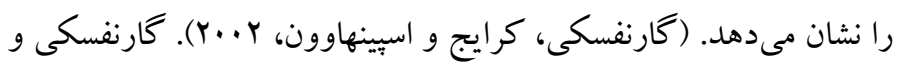
همكاران ( ( . . قابليت اعتماد اين آزمون را با استفاده از ضريب آلفاى كرونباخ 19/· · براى راهبردهاى سازشيافته و AV/· براى راهبردهاى

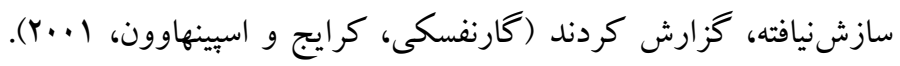

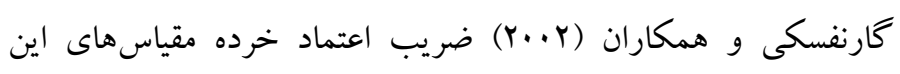
يرسشنامه را به شيوه باز آزمايى با فاصله زمانى fF أماه در ئزوهش در دامنه

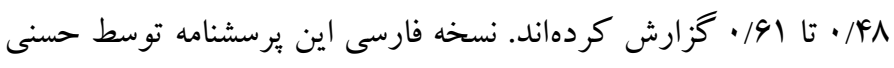

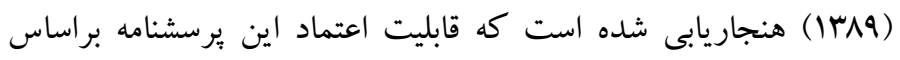
روش هاى همسانى درونى (با دامنه آلفاى كرونباخ V9/• تا Y99/•) و باز آزمايى (با دامنه همبستكى اه/ • تا NV/•) و درستى آن از طريق تحليل مؤلفه اصلى با استفاده از جرخش واريما كس، همبستكى بين خردهمقياس ها

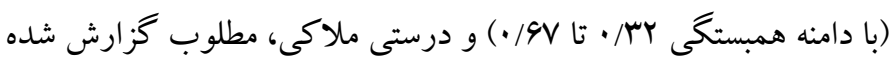

مصاحبه بالينى كو تاه־ (M.I.N.I-5): اين مصاحبه به عنوان يكك مصاحبه ساختاريافته براى اختلالات روانيزشكى محور يكك بر مبناى طبقهندى تشخيصى بين المللى DSM-5 و ICD طر احى شده است و توسط يعقوبى و همكاران ترجمه و بازبينى شده است (يعقوبى، آريانا كيا، طارميان، بيروى، حسن آبادى، و همكاران، و و SCIDID مقايسه كردهاند، نشان دهنده قابليت اعتماد و درستى قابل قبول اين مصاحبه است (لكوبير، شيهان، ويلر، آموريم، بونوراو همكاران،
كرونباخ •9/ • براى علايم اصلى و 91/· براى علايم فرعى به دست مى آمد. در يزوهش سرافراز و همكاران نيز آلفاى كرونباخ كل يرسشنامه برابر با AV/· • بود كه از حاكى از قابليت اعتماد مطلوب كل برسشنامه بود. بررسى هاى آمارى دادههاى اين يزٔوهش حاكى از درستى و قابليت اعتماد. مناسب برسشنامه بود (سرافراز، شهوند و زارعى، وهب1). يرسشنامه تحمل يريشانى '(DTS): اين ابزار خود كزارشى شامل ها هاده است كه ادراكك فرد را از توان تحمل رنج هيجانى، بر آورد ذهنى از درد، مقدار توجه معطوف شده به يريشانى، و تلاش براى تسكين تجربه يريشانى مورد ارزيابى قرار مىدهد. ياسخ هر يكك از مادهها با مقياس ليكرت، از 1 (به شدت موافق) تا ها (به شدت مخالف) سنجيده مىشود. نمرات بالا نشان دهنده تحمل يريشانى بيشتر و نمرات يايين نشان دهنده تحمل بريشانى بايين است. اين برسشنامه در سال ه ·. ب توسط سيمونز و كاهر ساخته شد. اين مقياس داراى جهار خرده مقياس مىباشد. كه خرده مقياس هاى آن عبارتند از: () تحمل، تحمل يريشانى هيجانى، Y) جذب، جذب شدن به وسيله هيجانات منفى، r) ارزيابى، برآورد ذهنى بريشانى و \&) تنظيم، تنظيم تلاشها براى تسكين يريشانى (سيمونز و كاهر، ه • ·Y). قابليت اعتماد اين

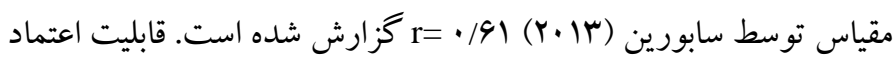
مقياس تحمل يريشانى و خرده مقياسهاى آن علاوه بر هنجار اوليه، در يُزوهش اندامى خشك (YMQY) به ترتيب تحمل بريشانى، تحمل، جذب،

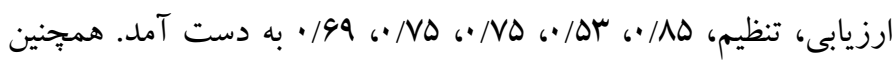
مشخص شده است كه اين مقياس داراى درستى ملاكى و همخراى اوليه خوبى است.

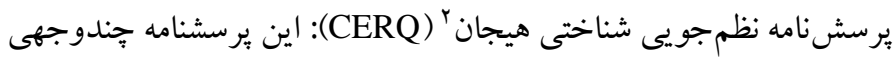
به منظور شناسايى راهبردهاى مقابله شناختى افراد يس از تجربه يك رويداد يا شر ايط منفى، مىباشد. برخلاف ديخر برسشنامها كه نمىتوان به روشنى بين افكار و اعمال افراد تمايز قائل شد، اين برسشنامه به طور انحصارى به افكار فرد بعد از تجربه كردن يكك رويداد منفى اشاره دارد. برسشنامه نظم جويى شناختى هيجان يكك يرسشنامه خودسنجى است كه متشكل از وب سؤال است كه بر مبناى نظرى و تجربى ساخته شده است و 9 استراتزى مقابله شناختى را اندازه كيرى مى كند. اين يرسشنامه شامل دو خرده مقياس

1. Distress Tolerance Scale

2 . Cognitive Emotion Regulation questionnaire 
از آن است كه تفاوت مشاهدهشه بين توزيع نمرات گروه نمونه و توزيع

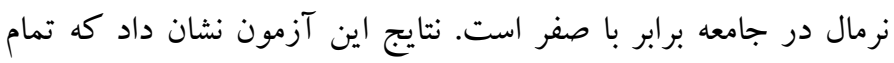

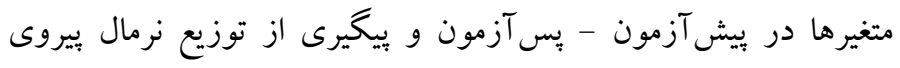

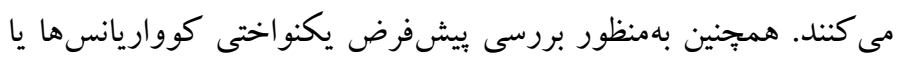

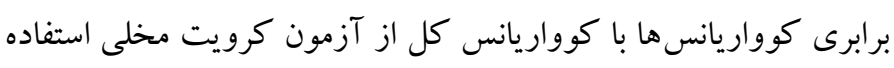

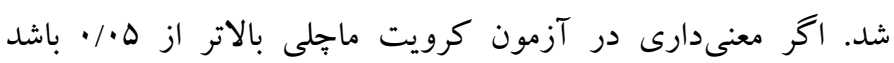
بهورمعمول از آزمون فرض كرويت و در صورت عدم دمر تأييد از آزمون

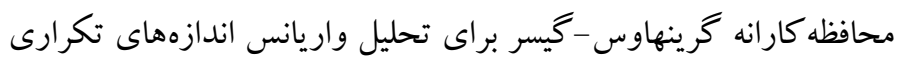
استفاده مىشود. كه از آنجا كه نتايج آزمون مخلى معنى دار بود (ه •/ P (P)

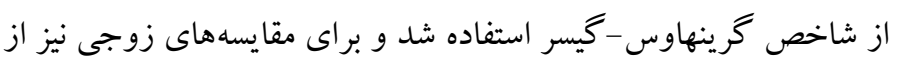

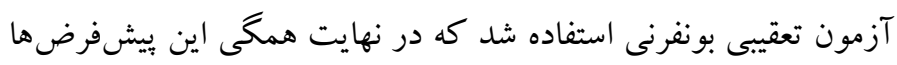

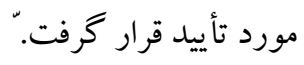
بر اساس نتايج جدول ب نمرات ميانگين نمرات متغير تحمل بريشانى در

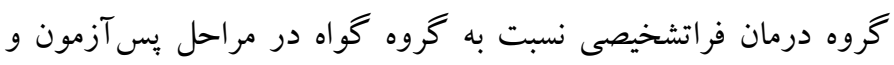

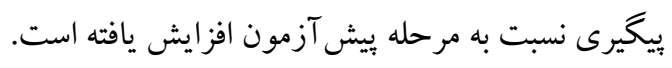

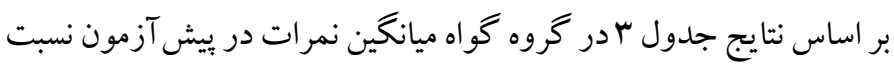

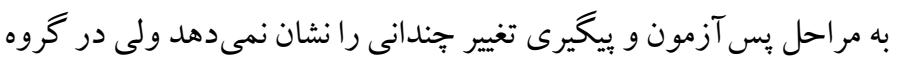

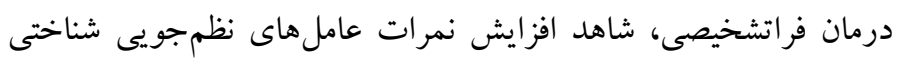

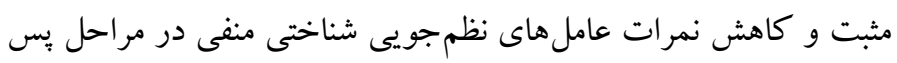
آزمون و بييخيرى نسبت به بيش آزمون هستيم.

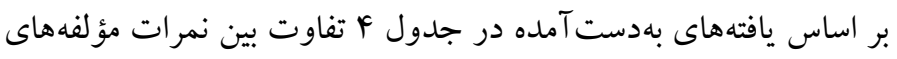

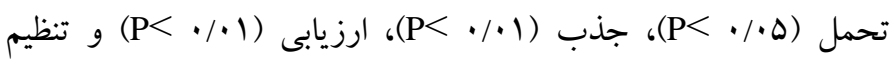
(P< در سه مرحله از بزوهش معنىدار است. نتايج نشان مىدهد كه

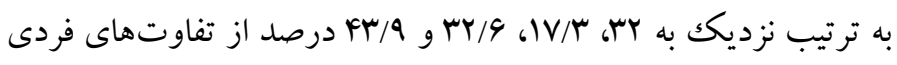

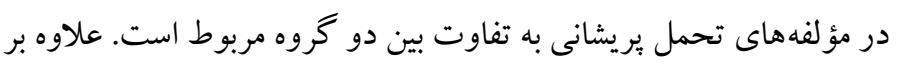

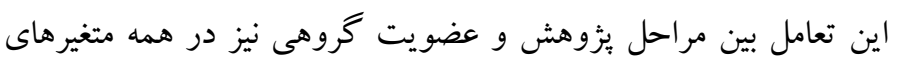

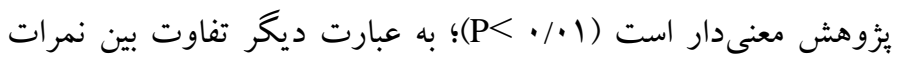

متغيرهاى بثزوهش در سه مرحله از يُزوهش در دو گروه معنى دار است.
يس از انجام نمونه گيرى، همه بيماران در يكك جلسه به صورت گروهى

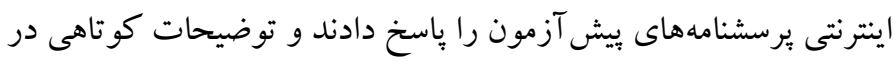
مورد نحوه تكميل يرسشنامهها داده شد تا دقت اجرا افزايش يابد. نهايتاً

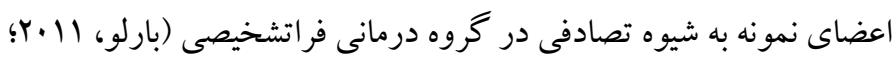

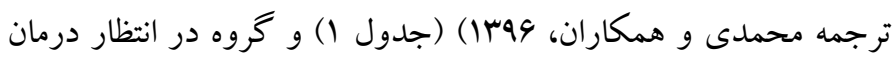

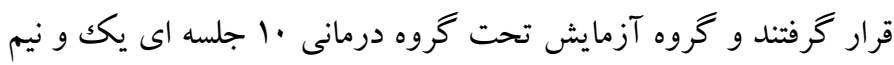

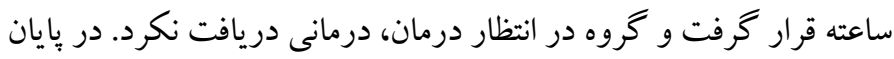

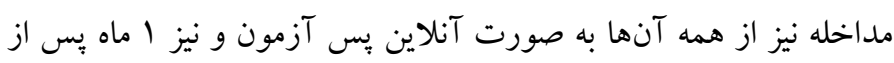

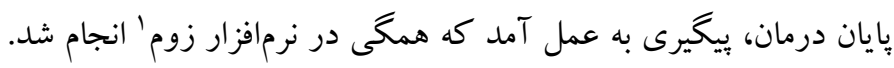

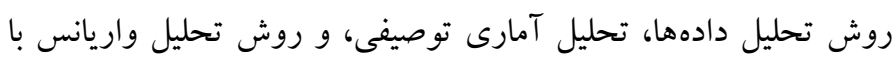

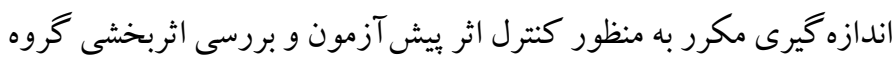

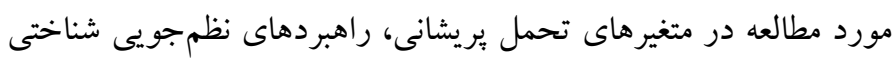

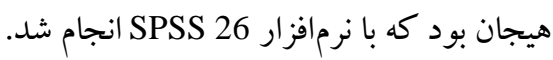

يافته ها نتايج يافته هاى توصيفى نشان داد ميانخين سنى شر كت كنند كان در گروه

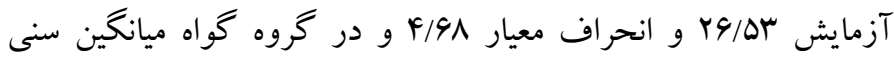

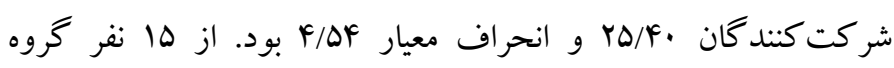

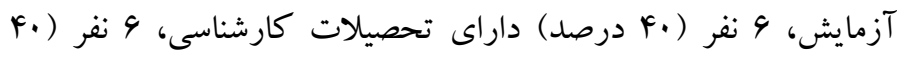

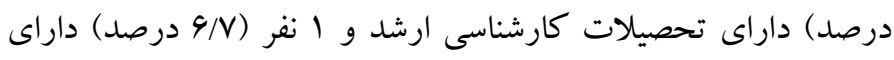
تحصيلات دكترى تخصصى و r نفر (r/rا درصد) و ا نفر (G/V) داراى

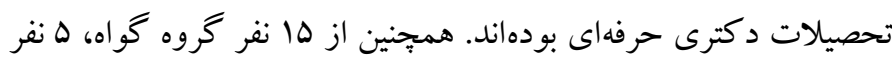

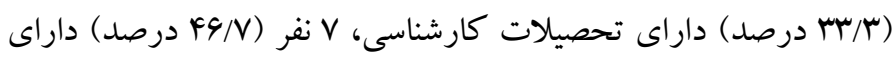
تحصيلات كارشناسى ارشد و r نفر (س/rا درصد) داراى تحصيلات

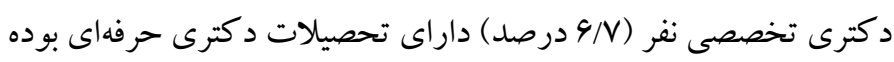

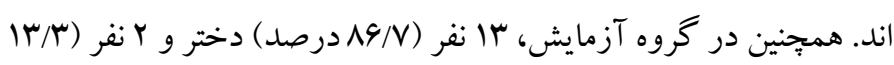

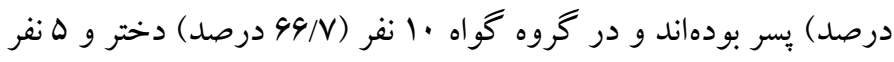

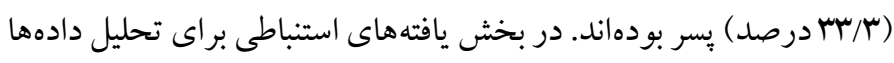

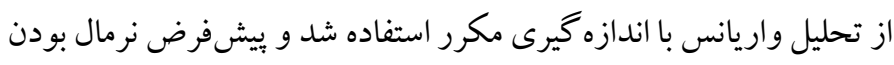

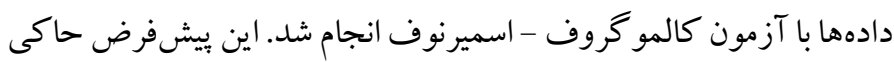




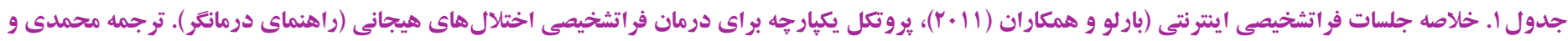
(1)

\begin{tabular}{|c|c|c|}
\hline ت تكاليف & 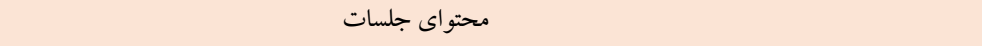 & جلسات \\
\hline آموزش ثبت و نظارت بر هيجانها & برقرارى اتحاد درمان و مرور علائم شكست عاطفى، ايجاد بيوستخى گروهى، خلاصهاى از طرح درمانى، & 1 \\
\hline آموزش ثبت و نظارت بر هيجانها & آموزش روانى در خصوص ماهيت هيجانها و تفكيك افكار از هيجان است و آشنايى با سه مؤلفه هيجان & r \\
\hline تكميل بر كه بيشايند، ياسخ، بيامد & افزايش آكاهى نسبت به ماشه جكانهاى تجارب هيجانى و پياسخها و شناسايى ييشايندها، پِاسخها و يِامدها & r \\
\hline تكميل فرم تجربه لحظه و ثبت القاى خلق / تكميل فرم & افزايش آكاهى غيرقضاوتى و لحظهاى از تجربيات هيجانى، جهتدهى به سمت اينجا و اكنون، برانخيختن & \\
\hline نظارت بر هيجانها و رفتارهاى هيجان خاست در زمينه & هيجانهاى مثبت و منفى، اجتناب از سر كوبى هيجانى & \\
\hline طرح داستانهايى با محتواى مثبت براى تصوير مبهم & 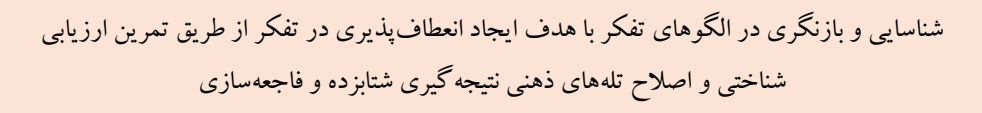 & $\Delta$ \\
\hline تكميل بركه راهبردهاى اجتناب از هيجانات & 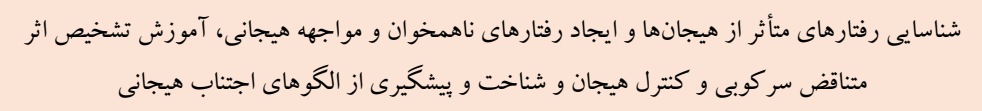 & 9 \\
\hline تكميل بر گه رفتارهاى هيجان خاست و بر گه تغيير آنها & شناسايى رفتارهاى هيجان خاست و لزوم مقابله با آنها و ايجاد عادت به انجام كنشهاى جايكزين، آكاهى & $\checkmark$ \\
\hline تكميل بركه آزمون القاى علائم و تمرينهاى مربوطه & 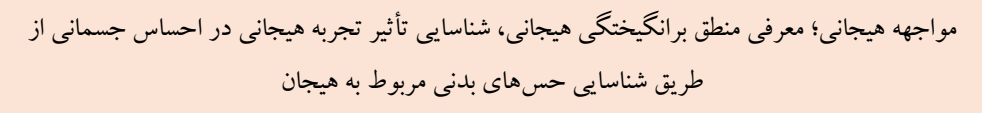 & $\wedge$ \\
\hline تكميل بر كه سلسله مر اتب اجتناب هيجانى و موقعيتى & مواجهه مكرر و نقش خو گيرى، ييشگيرى از اجتناب موقعيتى. ايجاد سلسله مراتب ترس و اجتناب و فراهم & 9 \\
\hline تكميل فرم ارزيابى ييشرفت، طرح تمرين، و فرم اهداف & 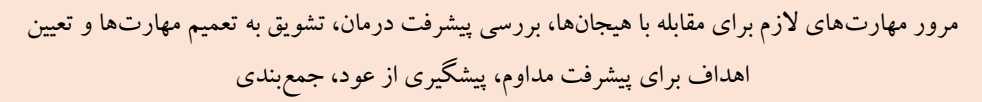 & 1. \\
\hline
\end{tabular}

جدول ז. شاخصهاى توصيفى نمرات متغير تحمل بريشانى در تروه بثوهش

\begin{tabular}{|c|c|c|c|c|c|c|c|}
\hline ييخيرى & & پֶ آزمون & & ييش آزمون & & & \\
\hline انحر اف استاندارد & ميانگين & انحر اف استاندارد & ميانگين & انحراف استاندارد & ميانگين & متغير & كروه \\
\hline$Q Y F / Y$ & $F V / q$ & $. \Delta N / \pi$ & $r V / l$. & $99 \Delta / 1$ & $\Lambda V / \Delta$ & تحمل & \\
\hline $.99 / 4$ & $1 \pi / 1$ & $91 . / 4$ & $9 \mathrm{~V} / 1$. & VQN/T & $F \cdot / V$ & جذب & \\
\hline $.9 Y / 4$ & $r \cdot / \Lambda$ & $Y F \cdot / F$ & $F V / l q$ & VAr/D & $r V / T Q$ & ارزيابى & فراتشخيصى \\
\hline$r V \cdot / r$ & $\Lambda \mathrm{V} / \mathrm{q}$ & $Q Y F / Y$ & $\Delta r / l$. & $v a \Delta / r$ & $9 \mathrm{~V} / 9$ & نظم جويى & \\
\hline$\Delta V \Delta / \Lambda$ & $G V / A V$ & $\wedge 9 \mathrm{~V} / \mathrm{q}$ & $a r / \Delta$. & $V \mid r / q$ & $r \cdot / r \Delta$ & تحمل بريشانى & \\
\hline$৭ ৭ \diamond / 1$ & $1 \pi / N$ & $r \cdot . r$ & $\mathrm{AV} / \mathrm{G}$ & $994 / r$ & $\mathrm{rV} / \mathrm{A}$ & تحمل & \\
\hline$\vee \wedge ৭ / r$ & $9 \pi / \Lambda$ & $\Lambda V \cdot / r$ & $9 \mathrm{~V} / \mathrm{A}$ & $\Delta 9 \cdot / r$ & $1 r / \Lambda$ & جذب & \\
\hline$\wedge 9 \Delta / 4$ & qV/Tr & $\Lambda \Gamma N / F$ & $\Lambda V / \Lambda r$ & $\Delta q M / \Delta$ & Tr/lr & ارزيابى & كواه \\
\hline$. \Delta r / r$ & $V r / \Delta$ & rMr/r & $\mathrm{FV} / \mathrm{\Delta}$ & $\mid r T / r$ & $9 \mathrm{~V} / 9$ & نظم جويى & \\
\hline $11 \% / \Lambda$ & $F V / T \Delta$ & $r \cdot r / q$ & $\Lambda V / T r$ & $0 \cdot N / 9$ & $F \cdot / r q$ & تحمل يريشانى & \\
\hline
\end{tabular}

جدول ". شاخصهاى توصيفى نمرات راهبردهاى نظم جويى شناختى هيجانى در تروههاى يخوهش

\begin{tabular}{|c|c|c|c|c|c|c|c|}
\hline \multicolumn{2}{|c|}{ ييخيرى } & \multicolumn{2}{|c|}{ يس آزمون } & \multicolumn{2}{|c|}{ ي بيش آزمون } & & \\
\hline انحر اف استاندارد & ميانگين & انحراف استاندارد & ميانكين & انحر اف استاندارد & ميانكين & 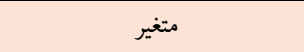 & \\
\hline$r / r q \Delta$ & $\mu \kappa / r$. & $k / 4 \cdot 9$ & $r \Delta / \mathrm{Fv}^{2}$ & $4 / .91$ & $r \cdot / v r$ & تمركز مثبت مجدد / برنامهريزى & \\
\hline$f / r \Delta Q$ & $r F / F$. & $r / v \Delta I$ & $r F / \cdot V$ & $r / \Delta \cdot r$ & $r \cdot / F V$ & ارزيابى مثبت / ديدگاه وسيعتر & ₹ \\
\hline v/avi & $\Delta N / 4$. & $v / r .$. & $\Delta Q / \Delta r$ & V/lkr & $\Delta 1 / r$ & نظمجويى شناختى مثبت & حروه \\
\hline l/arr & $N / F V$ & $r / r V F$ & Nar & $r / Y \Delta I$ & $I r / r V$ & سرزنش خود & \\
\hline
\end{tabular}




\begin{tabular}{|c|c|c|c|c|c|c|c|}
\hline \multicolumn{2}{|c|}{ ييخيرى } & \multicolumn{2}{|c|}{ يس } & \multicolumn{2}{|c|}{ ي بيش آزمون } & & \\
\hline انحر اف استاندارد & ميانگين & انحراف استاندارد & ميانگين & انحر اف استاندارد & ميانگين & متغير & \\
\hline $1 / 949$ & $N / F$. & $r / 910$ & $9 / \Delta r$ & $r / F V \Delta$ & $1 r / 1 r$ & سرزنش ديخران & \\
\hline$r / 1 \cdot \Delta$ & $\mid f / q r$ & r/GFY & $\mid f / F V$ & $r / 190$ & $1 \mathrm{~V} / \mathrm{s}$ & نشخو ار فكرى & \\
\hline r/aqR & $11 / 4$. & $r / F q F$ & $11 / \cdot v$ & $r / r r$. & $\mid f / 9 V$ & فاجعه آميز كردن & \\
\hline$r /$ rGF & $9 / 14$ & $r / \& q \Lambda$ & $9 / 9 V$ & $r / \wedge q$. & $I r / r v$ & يذيرش & \\
\hline N/AF & $\Delta r / \Delta r$ & $N / \Lambda \cdot \Delta$ & $\Delta r / q V$ & 9/9MT & $v \cdot / 9 r$ & نظمجويى شناختى منفى & \\
\hline$\Delta / 9 M$ & $r \mu / r v$ & $\Delta / F+q$ & $r r / \Delta r$ & $9 / 101$ & $\mu \kappa / r V$ & تمركز مثبت مجرد / برنامهريزى & فراتشخيصى \\
\hline 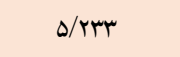 & $19 / 9 \mathrm{~V}$ & $\Delta / \Delta \cdot 9$ & $r \cdot / r$ & $\Delta / 4 a 9$ & $r / / \cdot v$ & ارزيابى مثبت / ديدكاه وسيعتر & \\
\hline$N / r / 9$ & $\Delta r / a r$ & $a /$ rar & $\Delta r / V r$ & $9 / 194$ & $\Delta \Delta / \mu$ & نظمجويى شناختى مثبت & \\
\hline $1 / v 1$ & $1 \cdot 1 \cdot v$ & $r / \Delta F I$ & $1 \cdot / \wedge$ & $r / . . \Delta$ & Q/^. & سرزنش خود & \\
\hline$r / 99$. & $1.19 \mathrm{~V}$ & r/var & $11 / \wedge$ & $r / v \wedge q$ & $11 / \cdot v$ & سرزنش ديخران & \\
\hline F/GFY & IV/or & $r / \wedge q \vee$ & W/AV & $r / f \Delta r$ & $W \cdot V$ & نشخوار فكرى & \\
\hline$r / 910$ & $10 / v r$ & $r / \Delta M$ & $1 \Delta / \Delta r$ & $r / \Delta \wedge \varphi$ & $10 / 4$ & فاجعه آميز كردن & 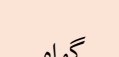 \\
\hline$r / 9 \wedge \Delta$ & $11 / v r$ & $r / .94$ & $\mid r / 4$ & $r / v r \Lambda$ & $\mid r / \cdot V$ & 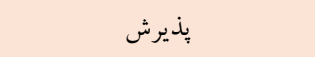 & \\
\hline $9 /$ rat & $90 / v r$ & $F / \Delta F A$ & $99 / 4$. & $\Delta / \Delta 9 \Delta$ & $99 / 4$ & نظمجويى شناختى منفى & \\
\hline$f / r q \Delta$ & $r F / r$. & $F / 4 \cdot 4$ & $r \Delta / q v$ & $f / .91$ & $r \cdot / v r$ & تمركز مثبت مجدد / برنامهريزى & \\
\hline
\end{tabular}

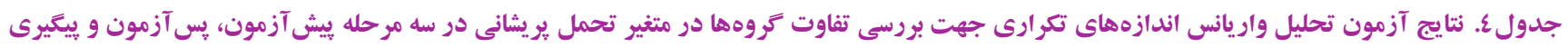

\begin{tabular}{|c|c|c|c|c|c|c|c|}
\hline ميزان تأثير & سطح معنى دارى & $\mathrm{F}$ & ميانگين مجذورات & $\mathrm{df}$ & مجموع مجذورات & منبع تغيير & متغير \\
\hline.$/ 11 r$ &.$/ .4 \Delta$ & $r / \Delta r q$ & $r \mathrm{r} / \wedge q \Lambda$ & $1 / 9 \mathrm{VA}$ & MN/FrY & مراحل & \\
\hline$\cdot / \cdot \wedge 1$ &.$/ M r A$ & $r / F \Delta \Delta$ & $r V / V V A$ & 1 & rV/VVA & كروهol & تحمل \\
\hline . &.$/ . .1$ & $1 r / 199$ & $\Lambda \Delta / / 99$ & $1 / 9 \mathrm{VA}$ & $\mid F Y / Q \Delta G$ & مراحل ** گروه & \\
\hline 每 & $.1 . .1$ & $\mid r / r F q$ & Fr/mrq & l/DQF & $q V / F \wedge q$ & مراحل & \\
\hline r & س &.$/ 9 \vee$ & $|0 / r| 1$ & 1 & $|0 / r| 1$ & كرووها & جذب \\
\hline.$/ \mathrm{Vrr}$ & $.1 \% 9$ & $\Delta / \wedge \Delta q$ & 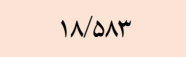 & 1/DQF & rQ/Grr & مراحل "* گروه & \\
\hline ./Y91 &.$/ .1$ & $1 . /$ rA & $\mathrm{rF} /$ QqF & $1 / W V^{F}$ & $9 \mathrm{r} / .9 \mathrm{~V}$ & مراحل & \\
\hline.$/ 1 \wedge 9$ &.$/ .18$ & $q /$ rva & Frg/AFF & 1 & Frg/NFF & كرووها & ارزيابى \\
\hline . /rYG &.$/ . .1$ & $|r / \Delta| V$ & FG/YFQ & $1 / V V F$ & $N r / \cdot r r$ & مراحل ** گروه & \\
\hline . MAr & $.1 . .4$ & G/rrA & $\mathrm{IV} / Q \Delta \mathrm{F}$ & I/VYA & rו/.rr & مراحل & \\
\hline.$/ 49 \Delta$ &.$/ . r$ & $11 / 119$ & $r 11 / 4 .$. & 1 & $r 11 / 4 .$. & كروهها & نظمجويى \\
\hline.$/ 4 r q$ &.$/ .1$ & rI/ATr & $9 H /|r|$ & I/VYA & $1.9 / .9 \mathrm{~V}$ & مراحل ** گروه & \\
\hline
\end{tabular}

جدوله. نتايج آزمون تحليل واريانس اندازههاى تكرارى جهت بروسى تفاوت تروهها در متغير راهبردهاى نظمجويى شناختى هيجانى در سه مرحله پيش آزمون، پي آزمون

\begin{tabular}{|c|c|c|c|c|c|c|c|}
\hline \multicolumn{8}{|c|}{ و ي ييگيرى } \\
\hline ميزان تأثير & سطح معنى دارى & $\mathrm{F}$ & ميانگين مجذورات & $\mathrm{df}$ & مجموع مجذورات & منبع تغيير & متغير \\
\hline$\cdot / / \wedge \Delta$ & $\% \vee v$ & $9 / \pi+9$ & $\mathrm{rq} / 99$. & I/DF. & $91 / \cdot 19$ & 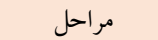 & \\
\hline.$/ .1$ & ./^९9 & 1.19 & $1 / 111$ & 1 & $1 / 111$ & كرومها & تمركز مثبت مجلد / برنامهريزى \\
\hline . RY. &.$/ .1$ & $\mid r / M M$ & $\Lambda r / \Delta \cdot \Lambda$ & I/DF. & $\mid r V / \cdot \wedge q$ & مر احل ** گروه & \\
\hline.$/ 1$ ro &.$/$ ro & $r / . . r$ & IV/AVD & $1 / 44 \lambda$ & MF/AYY & 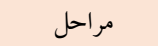 & \\
\hline.$/ .9$ & $\cdot / 1 \cdot 1$ & t/VGT & $19 . / \ldots$ & 1 & $19 . / \ldots$ & كروما & ارزيابى مثبت / ديد كاه وسيعتر \\
\hline 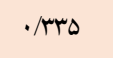 &.$/ .1$ & $|F /| r$. & $9 r / \cdot V 1$ & $1 / 94 \lambda$ & IYr/AgV & مر احل "* گروه & \\
\hline.$/ 411$ &.$/ .1$ & $1 Y / 901$ & $r V / a q I$ & I/NAY & FN/FYY & 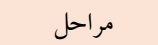 & سرزنش خود \\
\hline
\end{tabular}




\begin{tabular}{|c|c|c|c|c|c|c|c|}
\hline ميزان تأثير & سطح معنى دارى & $\mathrm{F}$ & ميانگين مجذورات & df & مجموع مجذورات & منبع تغيير & متغير \\
\hline 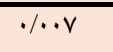 &.$/ 909$ &.$/ 199$ & $r / \Delta \cdots$ & $T$ & $r / \Delta \cdots$ & loog & \\
\hline.$/ F \Delta r$ & $\% 1$ & rr/Irg & $0 . / 499$ & I/VOr & $M N / F \& V$ & مر احل * گروه & \\
\hline . & $\% 1$ & $1 \Delta / r \Delta V$ & $\Delta r / \Lambda$. & $1 / 9 \cdot r$ & $Q ৭ / Y ९ \vee$ & مراحل & \\
\hline .1 .41 & . TrAr & $1 / 191$ & $|\Delta / r| \mid$ & 1 & $|\Delta / r| \mid$ & كرووها & سرزنش ديخران \\
\hline.$/ \mu F$. &.. .1 & $\mid k / F r$. & $r q / r \Delta r$ & $1 / 9 \cdot r$ & $9 r / M q$ & مر احل * كروه & \\
\hline.$/ 111$ &.$/ . r r$ & $r / N \Delta I$ & TI/ATF & I/Mr & $|4| / \cdot 19$ & مراحل & \\
\hline.$/ 1 F a$ & D מ ו & $r / q . r$ & $\mid r q / r V \wedge$ & 1 & $\mid r q / \pi v \wedge$ & كرووها & نشخوار فكرى \\
\hline.$/ 1 \Delta 9$ & .1 .99 & $\Delta / r \cdot \Lambda$ & $r \cdot / M q$ & l/Mur & $\Delta N / 1 \Delta \varphi$ & مر احل * گروه & \\
\hline . / Y99 & .1 .1 & $1 . / 210$ & $r V / r q \Delta$ & I/AYA & $0.1 .9 \mathrm{~V}$ & مراحل & \\
\hline ./r99 & $\% r$ & $11 / V 9 V$ & rIV/NVA & 1 & rIV/WVA & كرووها & فاجعه آميز كردن \\
\hline$\cdot / \pi r$. & $\% 1$ & $1 r / 19$ & $r \Delta / \cdot \mu$ & I/AYA & $q F / . r r$ & مر احل ** گروه & \\
\hline$\cdot / \kappa \wedge$. & .1 .1 & IV/Ir. & DI/TYY & I/DGY & $\Lambda \cdot / 109$ & مراحل & \\
\hline .1 .94 & .1 .99 & r/QIF & $F r / V I I$ & 1 & $F r / V I I$ & كرووها & ل يذيرش \\
\hline (5 & .1 .1 & $10 / 99$ & $F V / a \cdot \Lambda$ & I/DGY & VF/Arr & مر احل ** گروه & \\
\hline
\end{tabular}

يزؤهش و عضويت كروهى نيز در همه متغيرهاى بثزوهش معنى دار است

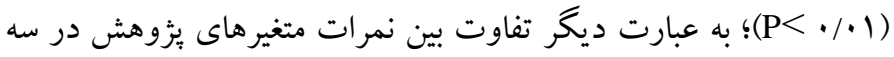
مرحله از يزوهش در دو گروه معنى دار است. با توجه به نتايج بهدست آمده در جدول بالا، تفاوت بين مراحل بيش آزمون، يس آزمون و بيگيرى در متغيرهاى ئزوهش معنى دار است؛ بنابراين نتايج مقايسهاى زوجى ميانكين هاى سه مرحله بثزوهش با استفاده از آزمون بونفرونى نشان مى دهد كه تفاوت مرحله بيش آزمون با دو مرحله يس آزمون و بيشيرى در كروه درمان فراتشخيصى معنى دار بهدست آمده است (1 ( نمر ات مؤلفه هاى تمر كز مثبت مجدد / بر نامهريزى و ارزيابى مثبت / ديد كاه وسيعتر در مراحل بِ آزمون و بيگيرى نسبت به مرحله يِش آزمون به طور معنى دارى افزايش يافته و ميانخين نمرات مؤلفههاى سرزنش خود، سرزنش ديخران، نشخوار فكرى، فاجعه آميز كردن و يذيرش در مراحل يس آزمون و بيخيرى نسبت به مرحله يِيش آزمون به طور معنى دارى كاهش يافته است. تفاوت بين نمرات مرحله يس آزمون با نمرات مرحله يِيَيرى در گرووه فر اتشخيصى معنى دار نيست (ه • • p > كه نشان دهنده ثبات اثرات درمان با كذشت زمان مىباشد. در گروه گواه تفاوت بين نمرات مرحله بيش آزمون با مراحل يس آزمون و بيخيرى و همجينين تفاوت بين نمرات

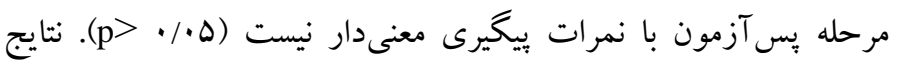
مقايسههاى زوجى با آزمون بونفرونى نشاندهنده معنىدارى تمركز مثبت

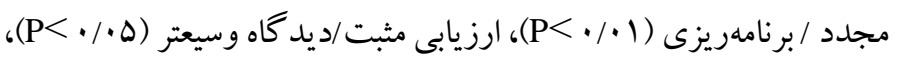

با توجه به نتايج بهدست آمده در جدول Fٔ، تفاوت بين مراحل بيش آزمون، بس آزمون و بيخيرى در متغيرهاى يزوهش معنى دار است. بنابراين نتايج مقايسه هاى زوجى ميانگين هاى سه مرحله بثوهش كه در سطح (ه • (P) معنىدار است با استفاده از آزمون بونفرونى بررسى شده است كه نتايج حاكى از معنى دارى تحمل (ه (P<)، جذب (P<) (P<) ارزيابى

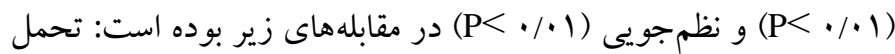
(ييش آزمون - بيخگيرى، يس آزمون - بيخيرى)، جذب (يس آزمون بيخيرى)، ارزيابى (ييش آزمون - يّ آزمون، بيش آزمون - ييكيرى) و نظم جويى (ييش آزمون - يس آزمون، يِش آزمون - يّيخيرى). نتايج آزمون تحليل واريانس اندازههاى تكرارى براى مقايسه دو گروه در متغير تحمل يريشانى در سه مرحله بيش آزمون - يس آزمون و يبگيرى در جدول كز ارش شده است. بر اساس يافته هاى بهدست آمده در جدول ه تفاوت بين نمرات مؤلفههاى تمركز مثبت مجدد / برنامهريزى (1 (P<)، ارزيابى مثبت / ديد

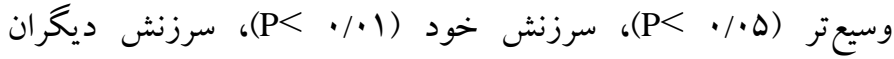

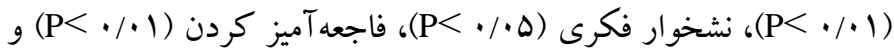

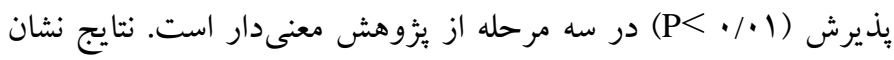
مىدهد كه به ترتيب نزديكك به Yr, ه/Wس، درصد از تفاوتهاى فردى در مؤلفههاى راهبردهاى نظمجويى شناختى هيجانى به تفاوت بين دو كروه مربوط است. علاوه بر اين تعامل بين مراحل 
همجنين نتايج تحليل نشان داد كه گروه درمانخرى فراتشخيصى بر

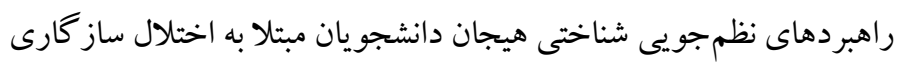

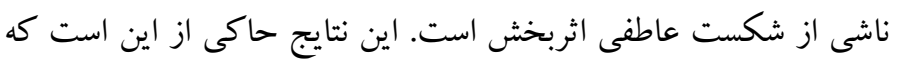

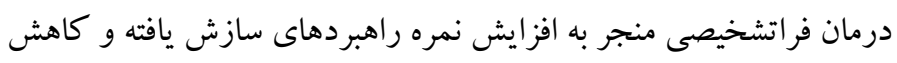
نمره راهبردهاى سازش نيافته نظمجويى شناختى هيجانى شده است و اين

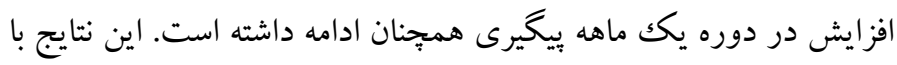

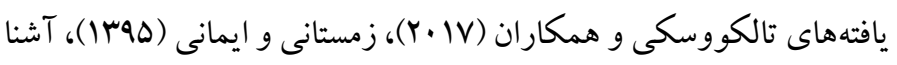

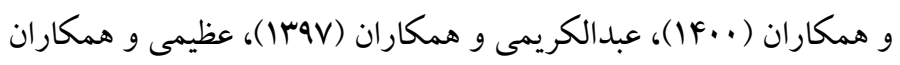

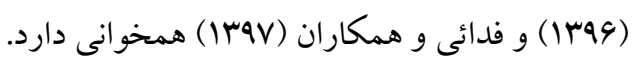

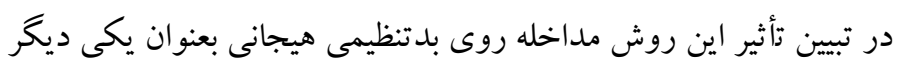

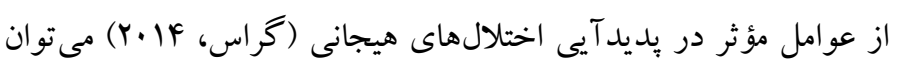

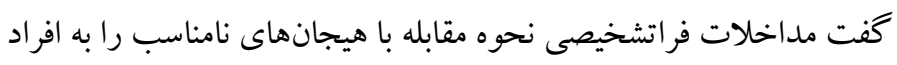

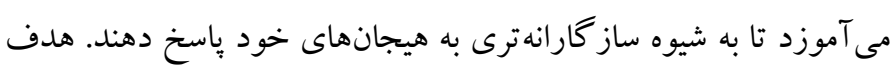

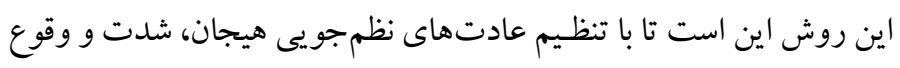

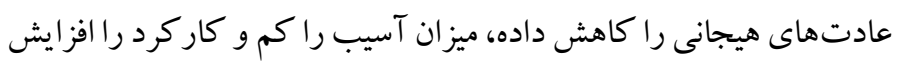

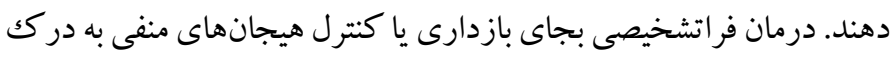

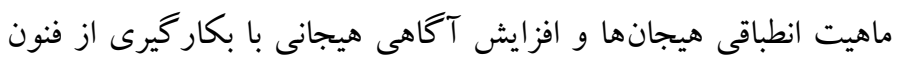

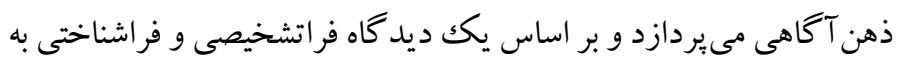
هيجانات مى يردازد و يكك سطح بالاتر از درمان صرف نظم جويى هيجان

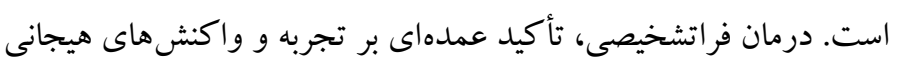
دارد؛ زيرا تلاش براى نظمجويى هيجانى موجب افزايش و و تداوم هيجان

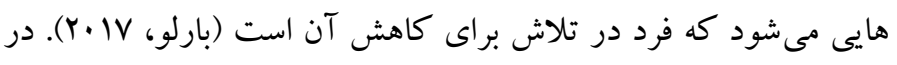

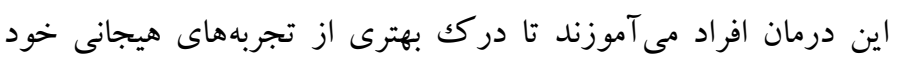

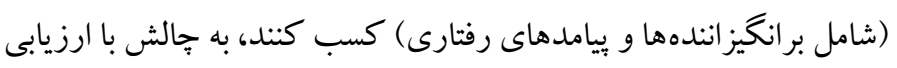
شناختى منفى احساسها و هيجانهاى جسمى خود بيردازند، رفتارهاى ناشى از هيجان را شناسايى و اصلاح كنند، آكاهى و تحمل احساسات جسمى در طى مواجهه درونزاد را كسب كنند و در بافتهاى موقعيتى و

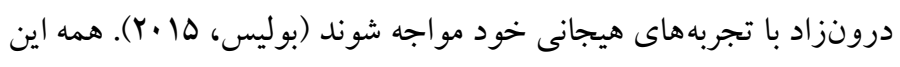
مهارتها، با اصلاح عادات نظمجويى هيجانى منجر به كاهش شدت هرت

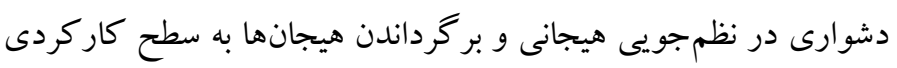
مىشود كه تأثير مستقيمى بر علائم هيجانى دارد (بخشى يور، عليلو، فرنام،

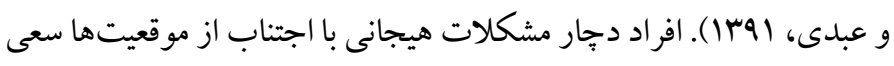

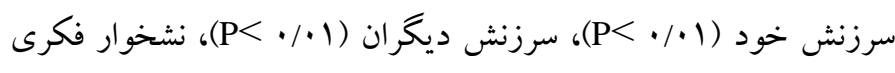

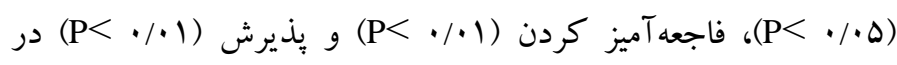

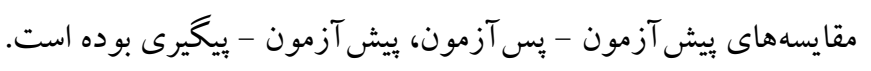

بحث و نتيجه تيرى هدف يُزوهش حاضر بررسى تأثير گروه درمانخرى فر اتشخيصى بر تحمل

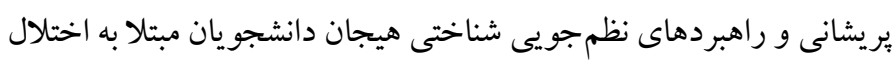

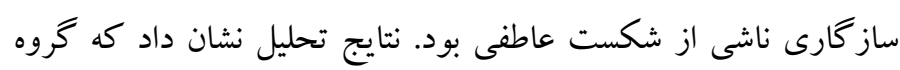
درمانگرى فراتشخيصى بر تحمل يريشانى دانشجويان مبتلا به اختلال ساز كارى ناشى از شكست عاطفى اثربخش است. اين نتايج با يافتهاى

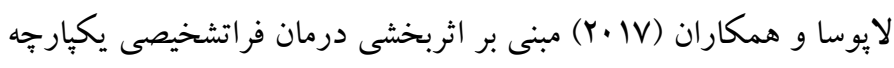
بر اختلالات اضطرابى و تحمل بريشانى و يُزوهش نر گسى و همكاران

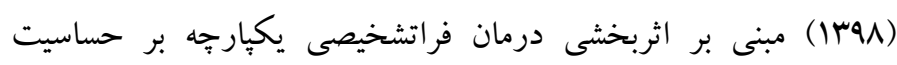

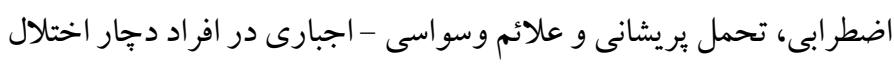

$$
\text { وسواسى اجبارى همسو است. }
$$

در تبيين نتيجه مذكور بايد اشاره نمود كه بايان يك هو رابطه عاشقانه خاص

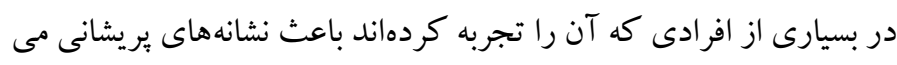

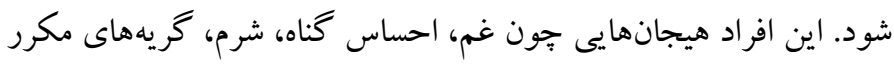

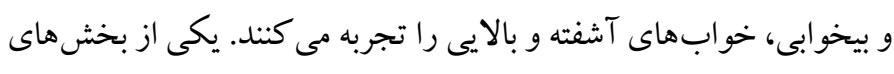

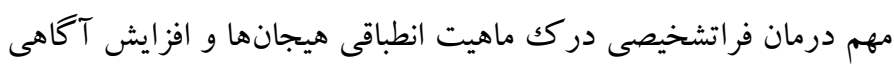

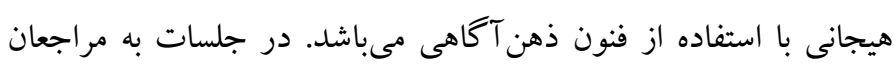

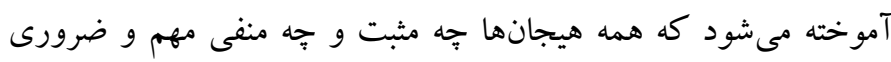

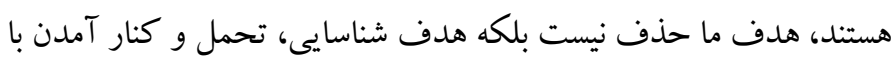

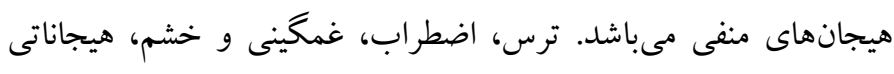

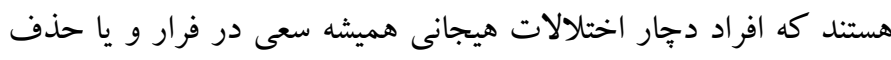
آنها را دارند در حالى كه اين هيجانات يكك مكانيزم حمايتى بوده، منجر

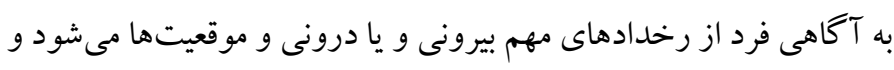

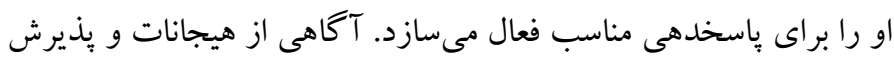

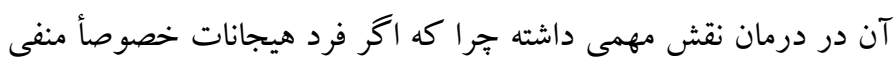

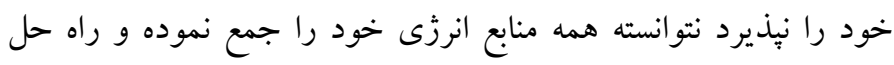

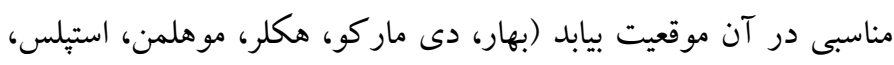
( $Y$. . Q 9 
عدم استفاده از نمونه گيرى تصادفى و عدم توجه به تفاوتهاى فرهنگى،

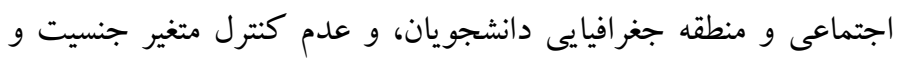
مقطع تحصيلى دانشجويان بود. لذا ييشنهاد مى شود اين درمانها روى نمونه

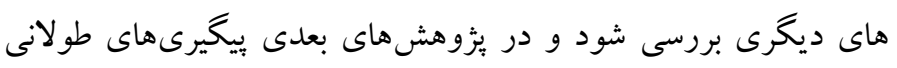

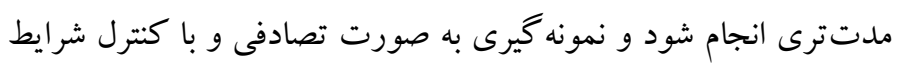

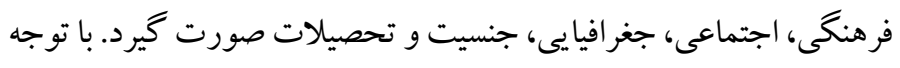

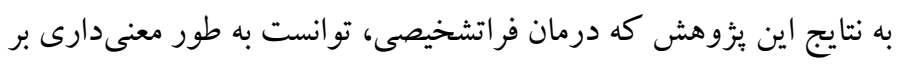
علايم ناشى از شكست عاطفى از جمله تحمل بريشانى و راهبردهاى نظم

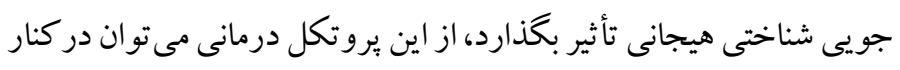
ساير يروتكل هاى درمانى براى شكست عاطفى استفاده كرد.

ملاحضات اخلاقى بيروى از اصول اخلاق يثوهش: اين مقاله بركرفته از رساله دكترى نويسنده اول در

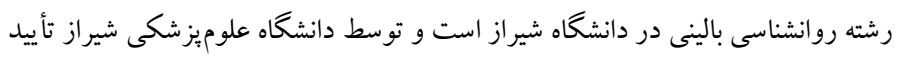
و داراى كد اخلاق IR.SUMS.REC.1400.070 مى مباشد. حامى مالى: اين يُوهش در قالب رساله دكترى و بدون حمايت مالى مى الشاشد.

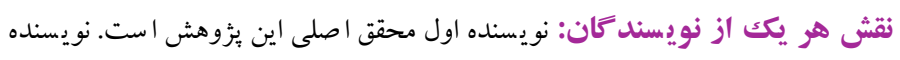

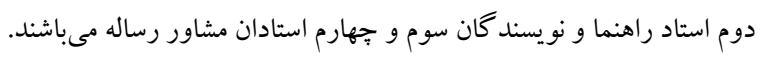

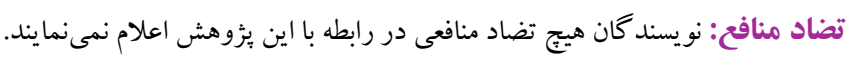

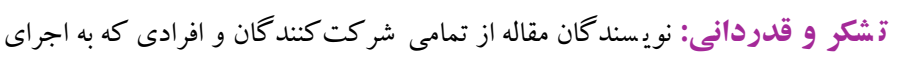
هرجه بهتر اين يزوهش كمك كردند صميمانه سياسكز ارى مىنمايند.
در فرار و حذف هيجانات منفى دارند و بسيارى از فرصت هاى زندگى خود

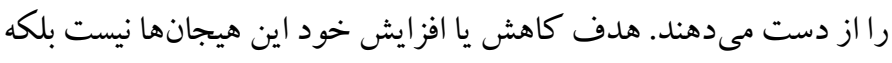
كاهش اجتناب و واكنش منفى به هيجانهاى منفى مىباشد. درمان

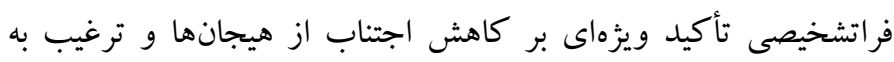

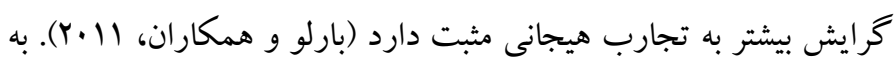

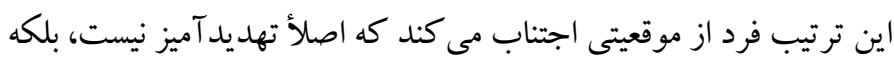

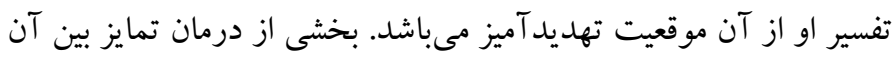

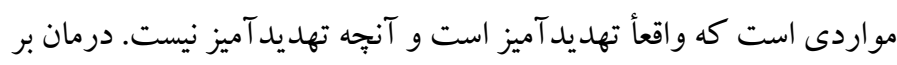

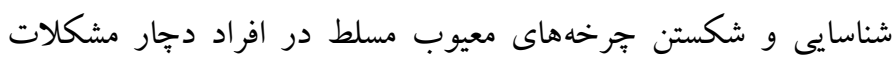

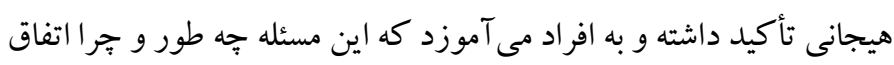

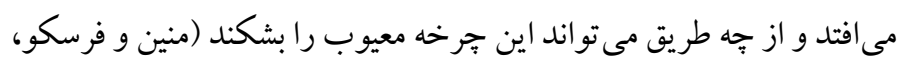

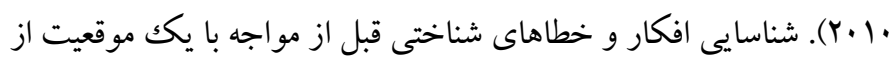

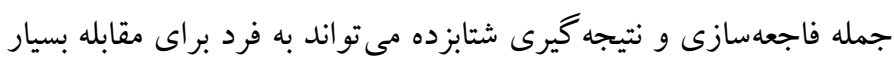

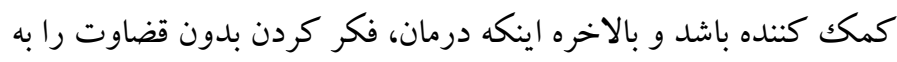

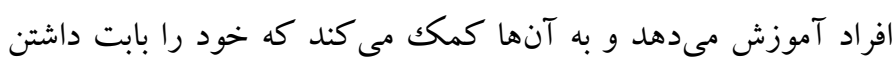

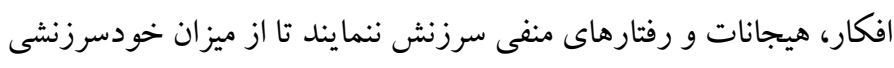

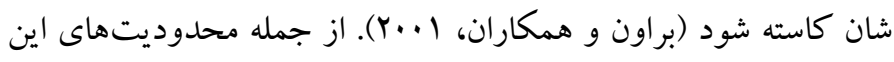

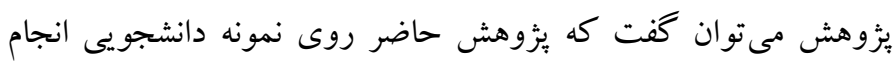

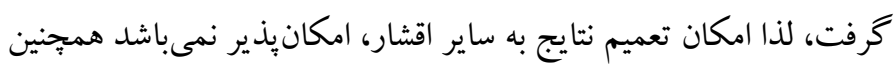

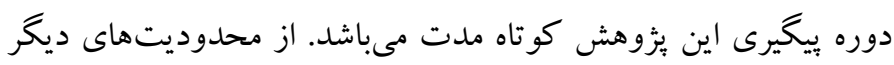




\section{References}

Abdolkarimi, M., Ghorban Shirodi, S., Khalatbari, J., Zarbakhsh, M. R. (2018). Effectiveness of meta diagnosis package of acceptance and commitment therapy, Self-Compassion therapy and dialectic behavioral therapy on emotion regulation and eating behavior of overweight and obese women. Journal of Psychological Science, 17 (70), 662-651. (Persian). [Link]

Azimi, A., Omidi, A., Shafiei, E., Nademi, A. (2018). The Effectiveness of Transdiagnostic, Emotion- focused Treatment for Emotional Regulation and Individual-social Adjustment in Female Students. J Arak Uni Med Sci. 20 (10), 62-73. (Persian). [Link]

Ashena, M., Besharat, M. A., Malihialzuckerini, S., Rafezi, Z. (2021). The effectiveness of unified transdiagnostic therapy on positive metacognitions and meta-emotions in mothers of children with cancer. Journal of Psychological Science, 20 (97), 13-22. (Persian). [Link]

Nargesi, F. fathiashtiani, A., davodi, I., ashrafi, E. (2019). The effect of unifled transdiagnostic treatment on anxiety sensitivity, distress tolerance and obsessivecompulsive symptoms in individuals with obsessive-compulsive disorder. 26 (2), 49-66. (Persian). [Link]

Bardeen, J. R., Kumpula, M. J., \& Orcutt, H. K. (2013). Emotion regulation difficulties as aprospective predictor of posttraumatic stresssymptoms following a mass shooting. Journal of Anxiety Disorders, 27, 188-196. [Link]

Barlow, F. (2017). The Unified PrOtOCO. Applications of the Unified Protocol for Transdiagnostic Treatment of Emotional Disorders, 291. [Link]

Behar, E., DiMarco, I. D., Hekler, E. B., Mohlman, J., \& Staples, A. M. (2009). Current theoretical models of generalized anxiety disorder (GAD): Conceptual review and treatment implications. Journal of anxiety disorders, 23(8), 1011-1023. [Link]

Brown, T. A., Campbell, L. A., Lehman, C. L., Grisham, J. R., \& Mancill, R. B. (2001). Current and lifetime comorbidity of the DSM-IV anxiety and mood disorders in a large clinical sample. Journal of abnormal psychology, 110(4), 585. [Link]

Bullis, J. R., Sauer-Zavala, S., Bentley, K. H., ThompsonHollands, J., Carl, J. R., \& Barlow, D. H. (2015). The unified protocol for transdiagnostic treatment of emotional disorders: preliminary exploration of effectiveness for group delivery. $J$ Behavior Modification, 39(2), 295-321. [Link]

Carpenter, J. K., Andrews, L. A., Witcraft, S. M., Powers, M. B., Smits, J. A. J., \& Hofmann, S. G. (2018). Cognitive behavioral therapy for anxiety and related disorders: A meta-analysis of randomized placebocontrolled trials. Depression and Anxiety, 35(6), 502-514. [Link]

Collins, T. J., \& Gillath, O. (2012). Attachment, breakup strategies, and associated outcomes: The effects of security enhancement on the selection of breakup strategies. Journal of Research in Personality, 46(2), 210-222. [Link]

Del Palacio-Gonzalez, A., Clark, D., O'Sullivan, L. (2017). Distress Severity Following a Romantic Breakup Is Associated With Positive Relationship Memories Among Emerging Adults. Emerging Adulthood, 5 (4), 267-259. [Link]

Fadaei, M., Ghanbari Hashem Abadi, B. A., Kimiaee, S. A. (2019).The efficacy of integrated meta-diagnosis therapy on their differentiation and the difficulty of regulating excitement in patients with anxiety syndrome. Medical Journal of Mashhad University of Medical Sciences, 61 (6), 1-11. (Persian). [Link]

Garnefski, N., Kraaij, V., \& Spinhoven, P. (2001). Negative life events, cognitive emotion regulation and emotional problems. Personality and Individual differences, 30(8), 1311-1327. [Link]

Garnefski, N., Kraaij, V., \& Spinhoven, P. (2002). CERQ: Manual for the use of the cognitive emotion regulation questionnaire, DATEC. Leiden University: The Netherlands. [Link]

Gilbert, S. P., \& Sifers, S. K. (2011). Bouncing back from a breakup: Attachment, time perspective, mental health, and romantic loss. Journal of College Student Psychotherapy, 25(4), 295-310. [Link]

Gross, J. J. (2014). Handbook of emotion regulation: Guilford publications. [Link]

Hasani, J. (2010). The psychometric properties of the cognitive emotion regulation questionnaire (CERQ). Journal of clinical psychology 2 (3), 7384. (Persian). [Link]

Hofmann, S. G., Sawyer, A. T., Fang, A., \& Asnaani, A . (2012). Emotion disregulation model of mood and anxiety disorders. Depression and Anxiety, 20(4), 590-556. [Link]

Johansson, R., Hesser, H., Ljótsson, B., Frederick, R. J., \& Andersson, G. (2012). Transdiagnostic, affectfocused, psychodynamic, guided self-help for depression and anxiety through the internet: study protocol for a randomised. BMJ Open, 2(6):e002167. [Link]

Knöpfli, B., Cullati, S., Courvoisier, D.S., BurtonJeangros, C., \& Perrig-Chiello, P. (2015). Marital breakup in later adulthood and self-rated health: a cross-sectional survey in Switzerland. International Journal of Public Health, 61, 357-366. [Link]

Laposa, J. M., Mancuso, E., Abraham, G., \& Loli-Dano, L. (2017). Unified protocol transdiagnostic 
treatment in group format: a preliminary investigation with anxious individuals. Journal of Behavior Modification, 41(2), 253-268. [Link]

Lecrubier, Y., Sheehan, D. V., Weiller, E., Amorim, P., Bonora, I., Sheehan, K. H., ... \& Dunbar, G. C. (1997). The Mini International Neuropsychiatric Interview (MINI). A short diagnostic structured interview: reliability and validity according to the CIDI. European psychiatry, 12(5), 224-231. [Link]

Lorenz, L., Bachem, R., Maercker, A. (2016). The adjustment disorder-new module 20 as a screening instrument: Cluster analysis and cut-off values. The International Journal of Occupational Environmental Medicine 7(4): 215-220. [Link]

McCarthy, G., \& Maughan, B. (2010). Negative childhood experiences and adult love relationships: The role of internal working models of attachment. Attachment \& Human Development, 12(5): 445461. [Link]

Mennin, D. S., \& Fresco, D. M. (2010). Emotion regulation as an integrative framework for understanding and treating psychopathology. In A. M. Kring \& D. M. Sloan (Eds.), Emotion regulation and psychopathology: A transdiagnostic approach to etiology and treatment (pp. 356-379). The Guilford Press. [Link]

Nargesi, F. fathi ashtiani, A., davodi, I., ashrafi, E. (2019). The effect of unifled transdiagnostic treatment on anxiety sensitivity, distress tolerance and obsessivecompulsive symptoms in individuals with obsessive-compulsive disorder. 26 (2), 49-66. (Persian). [Link]

Newby, J. M., McKinnon, A., Kuyken, W., Gilbody, S., Dalgleish, T. (2015). Systematic review and metaanalysis of transdiagnostic psychological treatments for anxiety and depressive disorders in adulthood. Clinical psychology review, 40, 91-110. [Link]

Norton, P. J. (2012). Group Cognitive-Behavioral Therapy of Anxiety: A Transdiagnostic Treatment Manual. Guilford Press. [Link]

Norton, P. J. Barrera, T .L. (2012). Transdiagnostic versus diagnosis-specefic CBT for anxiety disorders: A preliminary randomized controlled noninferiority trial. Depression and Anxiety, 29(10): 874-82. [Link]

Parkes, C .M. (2006). Love and loss: the roots of grief and its complications. First ed. Routledge. Taylor \& Francis Group. London and New York, 10-430. [Link]

Phillips, L. H. Henry, J. D. Nouzova, E. Cooper, C. Radlak, B. \& Summers, F. (2014). Difficulties with emotion regulation in multiple sclerosis: Links to executive function, mood, and quality of life.
Journal of Clinical and Experimental Neuropsychology, 36(8), 831-842. [Link]

Rahmat Jirdeh, S., Sodagar, S. A., \& Jomeheri, F. (2015). prediction of love affair failure based on styles of attachments and emotional blackmail. Indian Journal of Fundamental and Applied Life Sciences, 5(2), 2597- 2602. [Link]

Remuzzi, A., Remuzzi, G. (2020). COVID-19 and Italy: what next? Lancet (London, England). 395 (10231), P1225-1228. [Link]

Ryu, S., Chun, B. C. (2020). An interim review of the epidemiological characteristics of 2019 novel coronavirus. Epidemiology and health. 42. e2020006. [Link]

Sarafraz, M. R., Shahvand, T., Zarea, M. (2018). Psychometric properties of Adjustment Disorder New Model-20(ADNM-20). Journal of Clinical Psychology, 9 (34), 45-54. (Persian). [Link]

Sabourin, B. A. (2013). Can distress tolerance predict chronic worry? Investigating the relationships among worry, distress tolerance, cognitive avoidance, psychological flexibility, difficulties in emotion regulation, and anxiety sensitivity. Master' $\mathrm{s}$ Theses of science in Clinical-Behavioral Psychology. Master's Theses and Doctoral Dissertations. 550. [Link]

Simons, J. S., \& Gaher, R. M. (2005). The Distress Tolerance Scale: Development and validation of a self-report measure. Motivation and emotion, 29(2), 83-102. [Link]

Talkovsky, A. M., Green, K. L., Osegueda, A. and Norton, P. J. (2017). Secondary depression in transdiagnostic group cognitive behavioral therapy among individuals diagnosed with anxiety disorders. Journal of Anxiety Disorders, 46(9): 5664. [Link]

Titov, N., Dear, B. F., Schwencke, G., Andrews, G., Johnston, L., Craske, M. G., \& McEvoy, P. (2011). Transdiagnostic internet treatment for anxiety and depression: a randomised controlled trial. Behaviour research and therapy, 49(8), 441-452. [Link]

Watkins, E. (2015) .An Alternative Transdiagnostic Mechanistic Approach to Affective Disorders Illustrated With Research From Clinical Psychology. Emotion Review, 7(3), 250-255. [Link]

Zemestani, M., Imani, M. (2016). Effectiveness of transdiagnostic treatment on depression/anxiety symptoms and emotion regulation. Contemporary Psychology, 11 (1); 21-32. (Persian). [Link]

Zhu, H., Wei, L., Niu, P. (2020). The novel coronavirus outbreak in Wuhan, China. Global health research and policy. 5(1), 1-3. [Link] 